\title{
Polyethylene-Reflected Arrays of HEU (93.2) Metal Units Separated by Vermiculite
}

Mackenzie Gorham

John D. Bess

J. Blair Briggs

Reza Gouw

September 2010

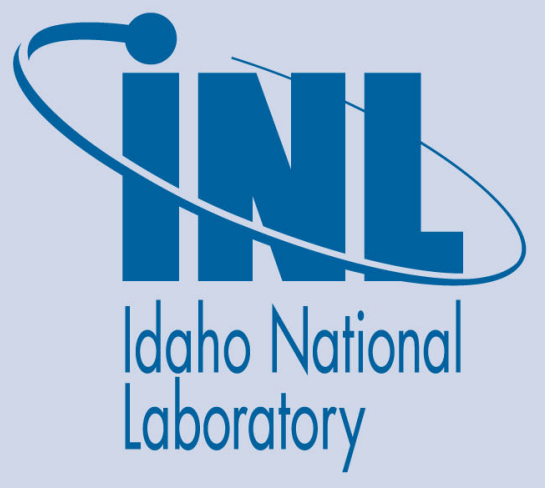

The INL is a U.S. Department of Energy National Laboratory operated by Battelle Energy Alliance 
INL/EXT-10-17644

\title{
Polyethylene-Reflected Arrays of HEU(93.2) Metal Units Separated by Vermiculite
}

\author{
Mackenzie Gorham ${ }^{1}$ \\ John D. Bess \\ J. Blair Briggs \\ Reza Gouw ${ }^{2}$ \\ ${ }^{1}$ Idaho State University/Idaho National Laboratory \\ ${ }^{2}$ Bettis Atomic Power Laboratory
}

September 2010

Idaho National Laboratory

Idaho Falls, Idaho 83415

http://www.inl.gov

Prepared for the

U.S. Department of Energy

Office of Nuclear Energy

Under DOE Idaho Operations Office

Contract DE-AC07-05ID14517 


\title{
POLYETHYLENE-REFLECTED ARRAYS OF HEU(93.2) METAL UNITS SEPARATED BY VERMICULITE
}

\author{
Evaluator \\ Mackenzie Gorham \\ Idaho State University \\ Idaho National Laboratory \\ Internal Reviewers \\ John D. Bess \\ J. Blair Briggs \\ Idaho National Laboratory
}

Independent Reviewer

Reza Gouw

Bettis Atomic Power Laboratory 


\title{
POLYETHYLENE-REFLECTED ARRAYS OF HEU(93.2) METAL UNITS SEPARATED BY VERMICULITE
}

\author{
IDENTIFICATION NUMBER: HEU-MET-FAST-056
}

SPECTRA

\begin{abstract}
KEYWORDS: acceptable, critical experiment, highly enriched, metal, polyethylene-moderated, polyethylene-reflected, uranium, vermiculite
\end{abstract}

\subsection{DETAILED DESCRIPTION}

\section{$1.1 \quad$ Overview of Experiment}

This report details the results of an experiment performed in the early 1970s as part of a series testing critical configurations in three dimensional arrays using a split table apparatus. For this experiment, cylinders of $93.2 \%$ enriched $\left({ }^{235} \mathrm{U}\right)$ uranium metal were arranged in a $2 \times 2 \times 2$ array inside a polyethylene reflector. Layers of vermiculite of varying heights were surrounding each cylinder to achieve criticality variations. A total of four experimental configurations were assembled by D. W. Magnuson and summarized in his experimental report "Critical Three-Dimensional Arrays of Neutron Interacting Units: Part IV. Arrays of U(93.2) Metal Reflected by Concrete and Arrays Separated by Vermiculite and Reflected by Polyethylene" (Ref. 1). These experiments were performed on the dates of November 1972 through December 1972 at the Oak Ridge Critical Experiments Facility (ORCEF). Details of the experiments are also provided in the experimental logbook. ${ }^{a}$ These experiments were performed to evaluate the effectiveness of vermiculite packaging material for the separation of fissile units in shipping containers. All four configurations are essentially the same (only very minor differences) so benchmark specifications are provided for only one. The experimental configuration was evaluated and determined to represent an acceptable benchmark experiment.

ICSBEP report, HEU-MET-FAST-054 is closely related; the results of both experiments are discussed in the same report (Ref. 1). Closely related work has been also been recorded in HEU-MET-FAST-053, which is an evaluation of a different series of three dimensional array experiments with four different moderator materials. HEU-MET-FAST-023 and HEU-MET-FAST-026 are also related because they utilize the same metal cylinders as these experiments.

\section{$1.2 \quad$ Description of Experimental Configuration}

The experiment consists of an almost square outer polyethylene reflector surrounding a $2 \times 2 \times 2$ array of 8 HEU metal cylinder pairs, with vermiculite sheets layered between the HEU cylinders and the polyethylene, and in between the cylinders themselves. Descriptive information was taken from the references and the experimental logbook.

1.2.1 HEU Metal Cylinders - For this series of experiments, eight 10.8-cm tall, highly enriched uranium (HEU) metal cylinder pairs with an outside diameter of $11.52 \mathrm{~cm}$ and a reported average mass of $20.962 \mathrm{~kg}$ (incorrectly reported as $20.962 \mathrm{~g}$ in the experimental report, but correctly recorded in the

\footnotetext{
${ }^{a}$ Oak Ridge National Laboratory Logbook 27r, pp 139-181.

http://www-rsicc.ornl.gov/CriticalExperiments/book27r.pdf. Accessed Summer 2010.
} 
logbook) were used to test critical arrangements of three dimensional arrays (Ref. 1). The cylinders were each constructed of two metal units stacked together to form a cylinder of the dimensions provided above; for this reason, these units are sometimes referred to as cylinder pairs.

The cylinders also have two small holes drilled through them, to allow for vertical placement on steel support tubes used in other experiments (HEU-MET-FAST-023 and HEU-MET-FAST-026). These holes run lengthwise through the cylinders with a diameter of $0.508 \mathrm{~cm}$ and are spaced $8.547 \mathrm{~cm}$ apart (Ref. 2). Support tubes were not used in this experiment, but the holes remain in the cylinders.

The measured mass of each cylinder pair, as well as the reported placement within the critical assembly is reported in Table 1. The cylinders always appear in pairs when discussed in the experimental report and logbook. The same practice is followed in this evaluation.

Table 1. Measured Mass of Large Uranium Cylinders (Ref. 1).

\begin{tabular}{|c|c|c|}
\hline Unit Number & Cylinder Pair & $\begin{array}{c}\text { Mass } \\
\text { (kg) }\end{array}$ \\
\hline \hline 1 & 2176 and 2189 & 20.966 \\
\hline 2 & 2204 and 2205 & 20.966 \\
\hline 3 & 2168 and 2193 & 20.963 \\
\hline 4 & 2195 and 2198 & 20.962 \\
\hline 5 & 2170 and 2152 & 20.960 \\
\hline 6 & 2156 and 2200 & 20.959 \\
\hline 7 & 2162 and 2190 & 20.962 \\
\hline 8 & 2172 and 2197 & 20.961 \\
\hline
\end{tabular}

1.2.2 Vermiculite Blocks - The packing material contained vermiculite, plyamine, and $\mathrm{NH}_{4} \mathrm{Cl}$ and was acquired in the form of 1- and 2-inch-thick squares, 10 inches on a side. At other times, the pieces were referred to as plyamine-bonded sheets of vermiculite. These pieces were later cut by hand into sizes appropriate for the needs of the experiment. The squares were described as "quite friable" and "not suitable for structural support" (Ref. 1). There were several comments in the logbook regarding the vermiculite being of low quality. The logbook also states that the pieces were cut to reduce the square edges to a uniform 9.5 inches using a band saw.

It is also stated that vermiculite pieces were chosen for use based on achieving a uniform thickness in layers as much as possible, and while the volume error might be large, the total amount of material in the region between units was determined by weight and chemical analyses.

Sketches in the logbooks indicate that the vermiculite might have been arranged with a small gap in the $\mathrm{x}$ direction, between the two halves of the experiments; or with gaps running in both the $\mathrm{x}$ and $\mathrm{y}$ directions, surrounding each cell. There are also small $0.32 \mathrm{~cm}$ gaps between the vermiculite and the reflector along inner edge of the reflector.

1.2.3 Polyethylene Reflector - The polyethylene reflector surrounded the experimental array on all sides (Ref. 1.). On page 5 of the experimental report (in Footnote e at the bottom of Table 1), the experimenter states that the reflector "was $15.24 \mathrm{~cm}$ thick or greater except for two sides where the thickness was $14.60 \mathrm{~cm}$." The logbook offers no insights on which were the smaller sides. 


\section{HEU-MET-FAST-056}

1.2.4 Assembly Description - The experimenter layered vermiculite under, beside, and over the bottom four uranium pieces on two halves of a split table apparatus. The experimenter notes that the uranium was centered horizontally within the stacks of vermiculite as much as possible. To create criticality changes, the top layer of uranium was surrounded by varying heights of vermiculite pieces. The outer dimensions of the vermiculite in each configuration are detailed in Table 2. The inner dimensions can be derived through these given dimensions and the KENO-format descriptions listed in Table 1 of the experimental report.

Table 2. Vermiculite Dimensions in Centimeters.

\begin{tabular}{|c|c|c||}
\hline $\begin{array}{c}\text { Length } \\
\text { (X Direction) }\end{array}$ & $\begin{array}{c}\text { Width } \\
\text { (Y Direction) }\end{array}$ & $\begin{array}{c}\text { Height } \\
\text { (Z Direction) }\end{array}$ \\
\hline 22.86 & 22.86 & $\begin{array}{c}22.86, \text { except when varied } \\
\text { over specific array locations }\end{array}$ \\
\hline
\end{tabular}

The outer dimensions of the reflector did not change between experiments. The vermiculite layers surrounding the bottom four cells also remained constant for all four configurations. Only the top cells were perturbed to produce different critical configurations. The vermiculite layer on top of the uranium cylinders was $1.9 \mathrm{~cm}$ thicker than the vermiculite layers on the bottom, though the perturbations to the vermiculite layers changed this value as indicated in the following tables and images.

Each cell is described by the uranium cylinder, the surrounding vermiculite layers, and the associated gap between the cylinder and the vermiculite. Experiment 18 was a base configuration with all eight cells having the same dimensions; and was the evaluated experiment for this benchmark report. Alterations in individual cells on the top layer created the additional experimental configurations. The cells for each experiment are dimensionally described in Table 3. This table lists the dimensions to the outside of the vermiculite sheets for each cell, and does not include the reflector

Table 3. Overall Experimental Cell Dimensions ${ }^{(\mathrm{a})}(\mathrm{cm})$.

\begin{tabular}{|c|c|c|c|c|}
\hline Experiment & Top Right Front & Top Left Front & Top Right Back & Top Left Back \\
\hline \hline 18 & $22.86 \times 22.86 \times 22.86$ & $22.86 \times 22.86 \times 22.86$ & $22.86 \times 22.86 \times 22.86$ & $22.86 \times 22.86 \times 22.86$ \\
\hline 19 & $22.86 \times 22.86 \times 20.83$ & $22.86 \times 22.86 \times 22.86$ & $22.86 \times 22.86 \times 20.83$ & $22.86 \times 22.86 \times 22.86$ \\
\hline 20 & $22.86 \times 22.86 \times 15.98$ & $22.86 \times 22.86 \times 22.86$ & $22.86 \times 22.86 \times 15.98$ & $22.86 \times 22.86 \times 22.86$ \\
\hline 21 & $22.86 \times 22.86 \times 15.88$ & $22.86 \times 22.86 \times 22.86$ & $22.86 \times 22.86 \times 22.86$ & $22.86 \times 22.86 \times 22.86$ \\
\hline
\end{tabular}

(a) The logbook does not contain a sketch which shows all dimensional data on one image. Partial sketches can be found on logbook pages 175, 177, 179, 181, 185, 188, 191, 193, and 200, but these sketches often do not match each other nor do they match completely the data from Table 1 of the experimental report. It is assumed that the experimenter made sketches of several permutations, not all of which were included in the final report.

As mentioned previously the vermiculite was cut by hand, causing it to be very uneven and irregular, creating several gaps in the structure. Because the vermiculite was so uneven, there is some uncertainty in the dimensions of the small gaps between the stacks of vermiculite, and between the polyethylene and the vermiculite. This uncertainty is discussed in detail in Section 2.2.3; it is noted here because in Figures 1 - 8 the gap is shown, but not dimensioned due to this uncertainty. These images assume that the experimenter placed the vermiculite pieces against the edge of the polyethylene, and the widest gap is between the middle stacks of vermiculite, though there may be gaps between the vermiculite stacks and

Revision: 0 


\section{NEA/NSC/DOC/(95)03/II \\ Volume II}

HEU-MET-FAST-056

the polyethylene reflector. Based on logbook sketches, and knowledge of split table machines, it is likely the gap was more in the center rather than at the edges of the vermiculite. ${ }^{\mathrm{a}}$

The uranium and vermiculite pieces were surrounded by a polyethylene reflector that was $15.24 \mathrm{~cm}$ thick or greater on all but two sides, where it was $14.60 \mathrm{~cm}$ (Ref. 1). However, the experimenter made all sketches using an approximate $15 \mathrm{~cm}$ thickness, and used $15 \mathrm{~cm}$ for all calculations, and the following images depicting the experimental configurations use the same convention.

According to the logbook "the distances separating the fissile units are averages for the 8-unit arrays", and these distances are within $\pm 0.06 \mathrm{~cm}$ of the reported values. The geometry of the vermiculite is known within $\pm 0.2 \mathrm{~cm}$. The location of the surface of the polyethylene is known to $\pm 0.05 \mathrm{~cm}$. Because of the friable condition and irregular geometry of the vermiculite, the accuracy of the experiment is not as good as in air-spaced or other previously assembled arrays with these metal units.

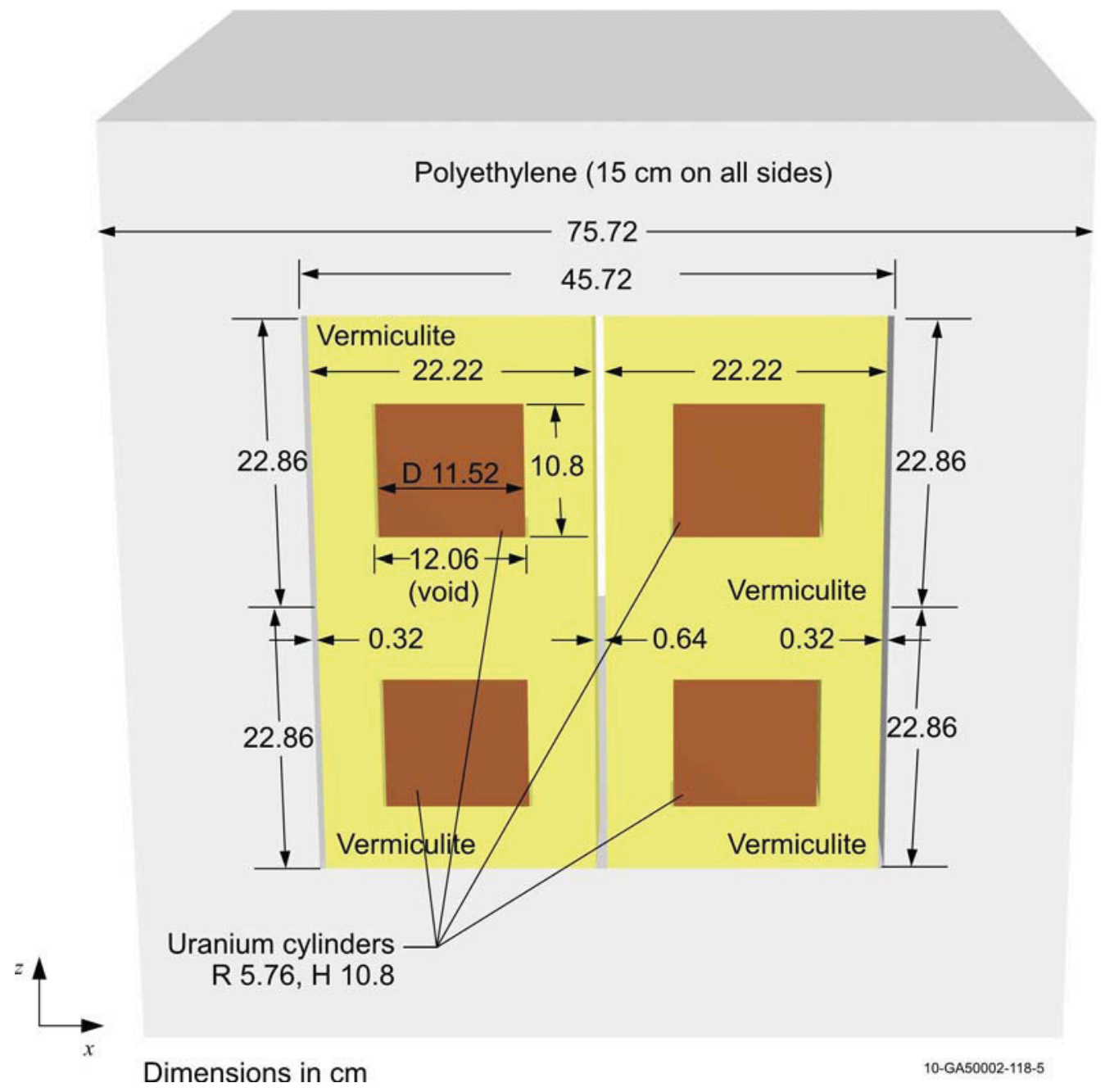

Figure 1. Configuration 18 - Front View.

${ }^{a}$ ORNL Critical Experiments Logbook 27r, p 161. 


\section{NEA/NSC/DOC/(95)03/II \\ Volume II}

\section{HEU-MET-FAST-056}

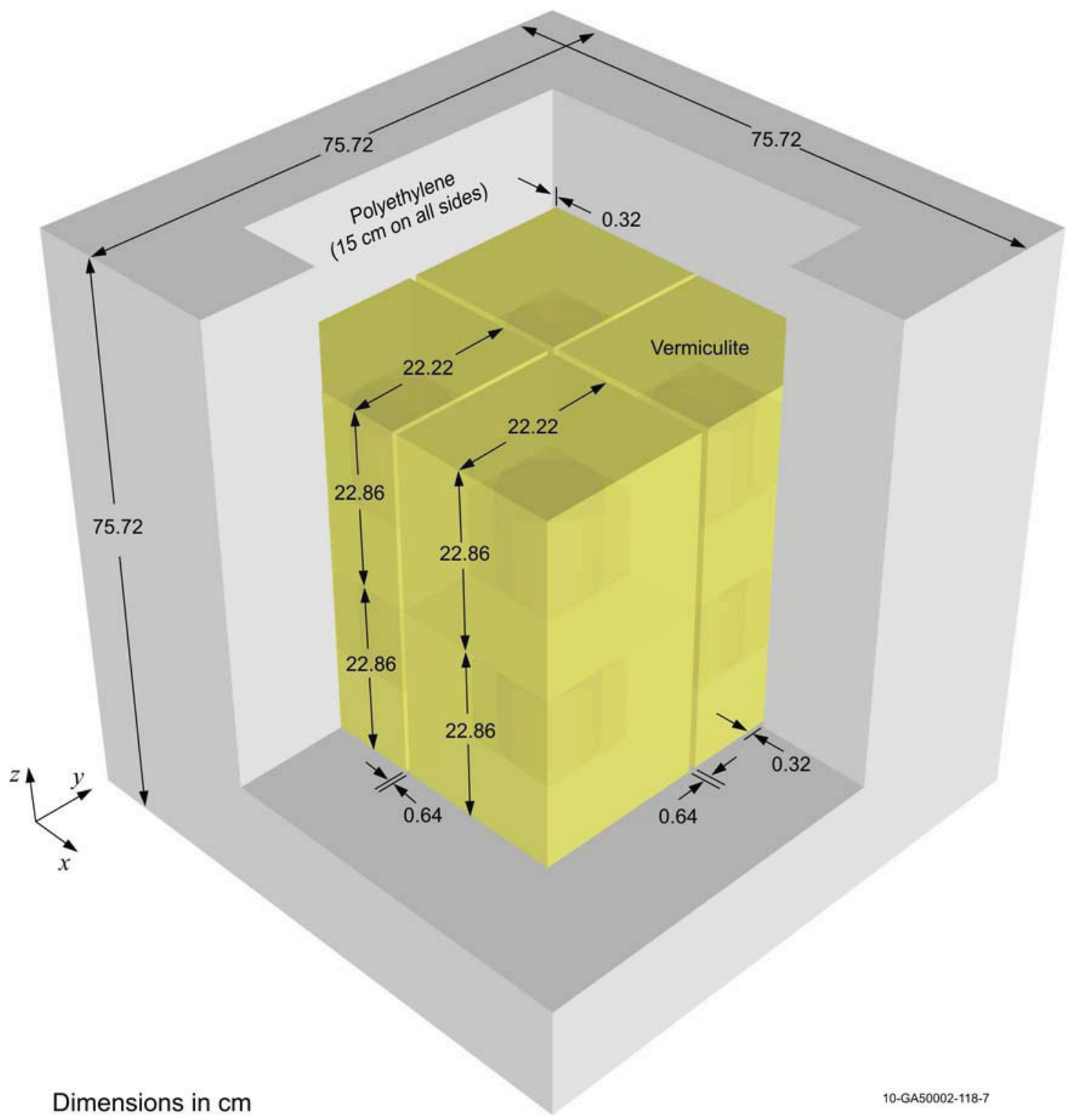

Figure 2. Configuration 18 - Overview. 
NEA/NSC/DOC/(95)03/II
Volume II

HEU-MET-FAST-056

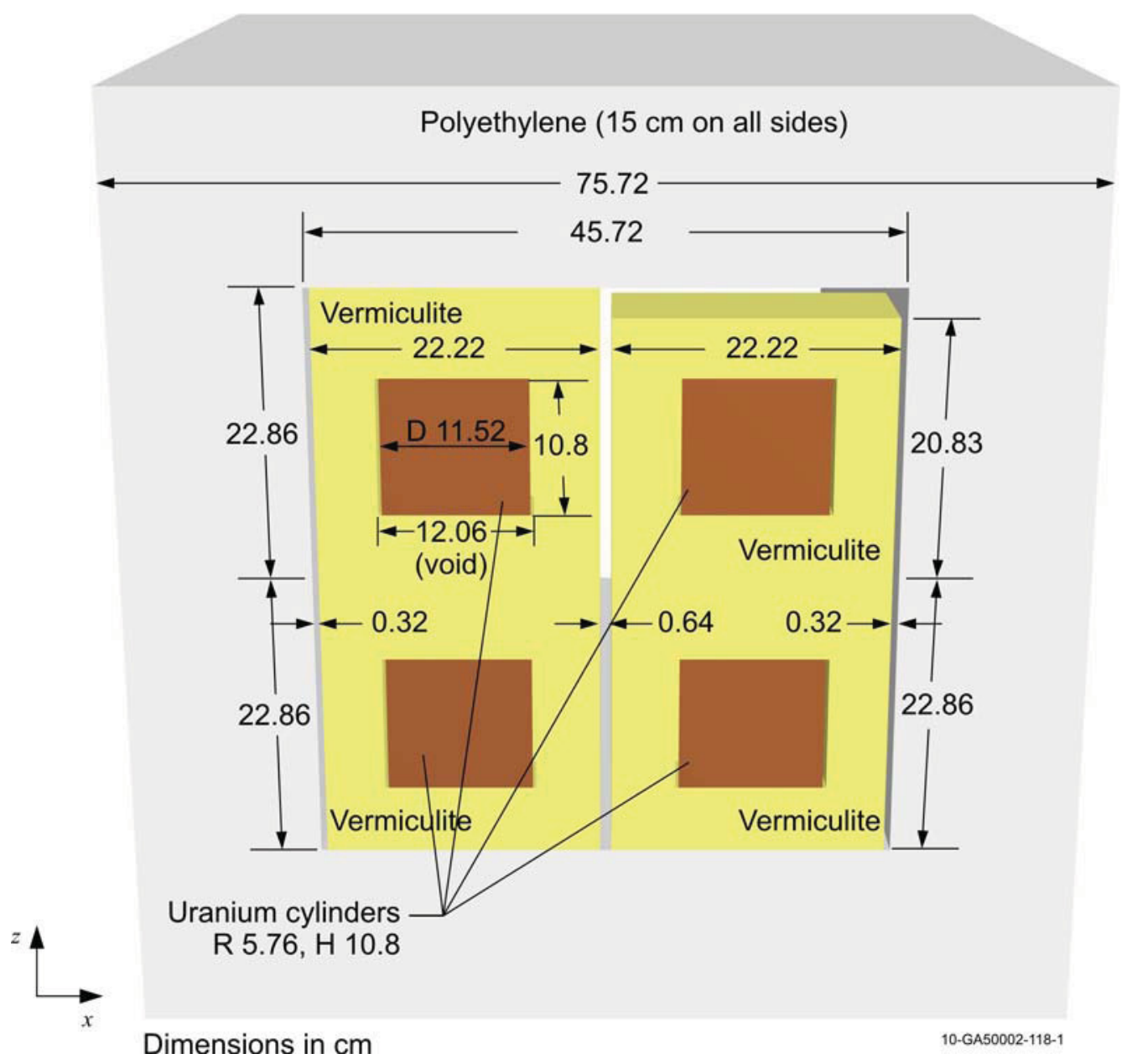

Figure 3. Configuration 19 - Front View. 


\section{NEA/NSC/DOC/(95)03/II \\ Volume II}

\section{HEU-MET-FAST-056}

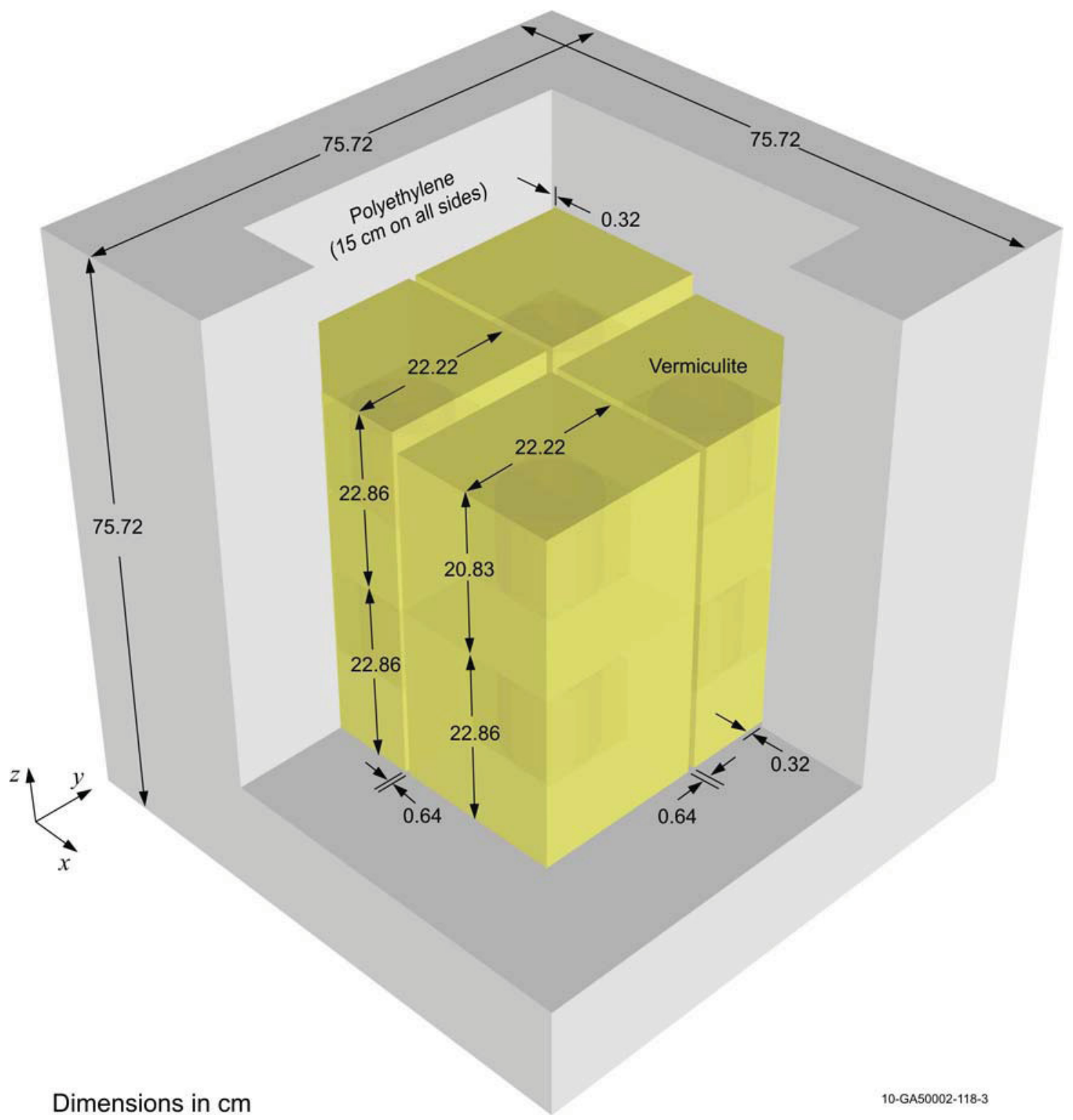

Figure 4. Configuration 19 - Overview. 
NEA/NSC/DOC/(95)03/II
Volume II

HEU-MET-FAST-056

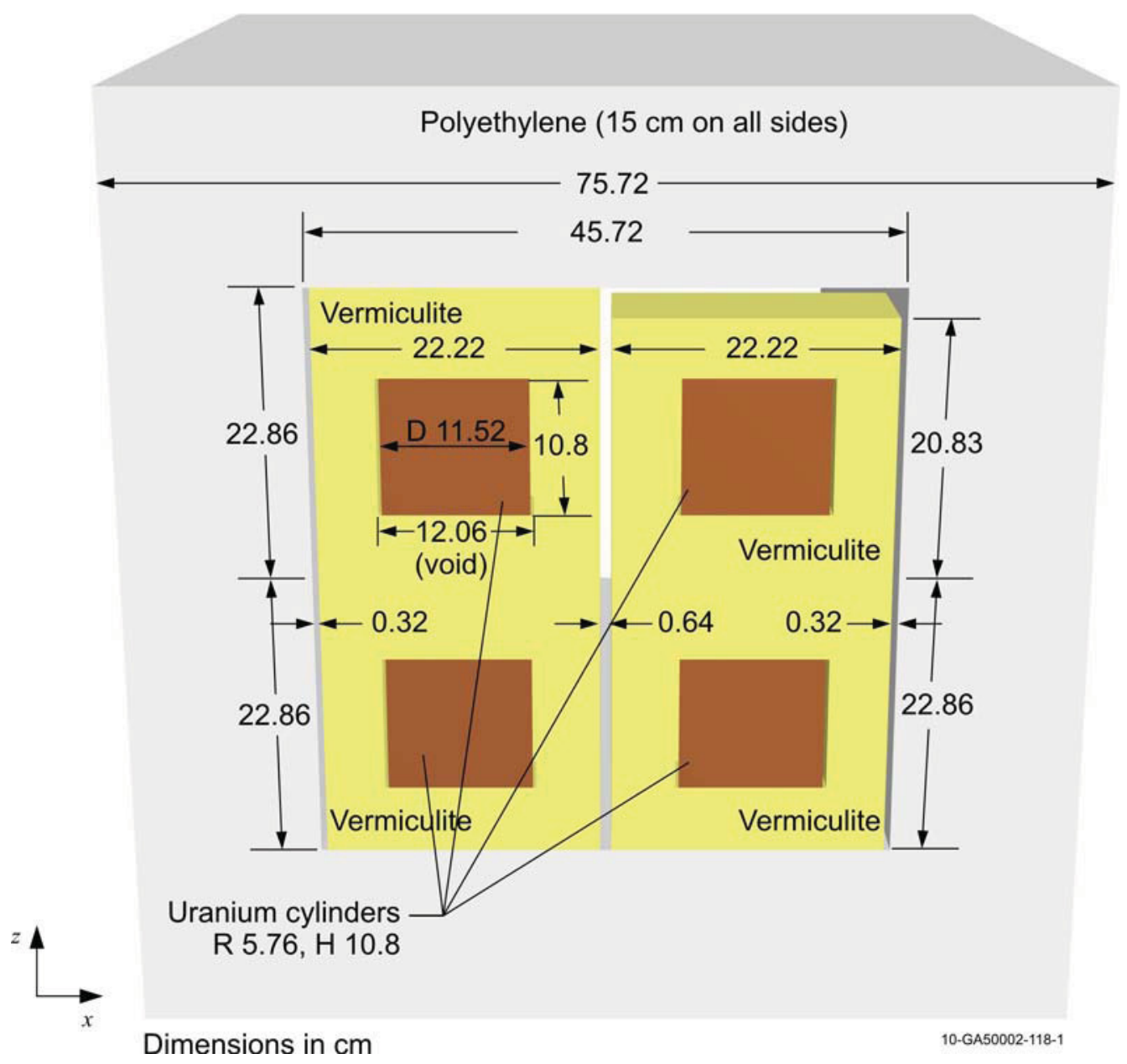

Figure 5. Configuration 20 - Front View. 


\section{NEA/NSC/DOC/(95)03/II \\ Volume II}

\section{HEU-MET-FAST-056}

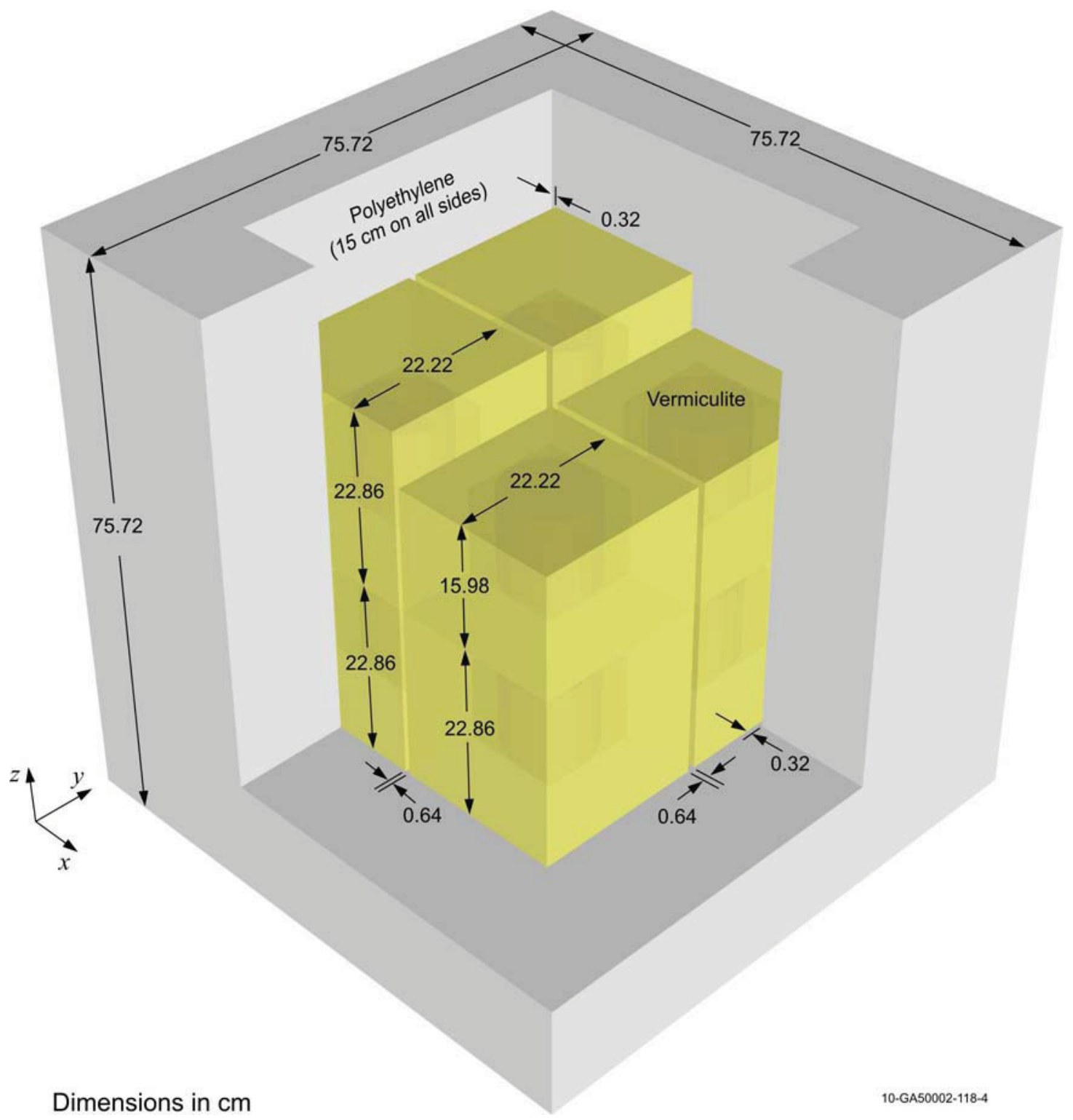

Figure 6. Configuration 20 - Front View. 
NEA/NSC/DOC/(95)03/II

Volume II

HEU-MET-FAST-056

Polyethylene (15 $\mathrm{cm}$ on all sides)

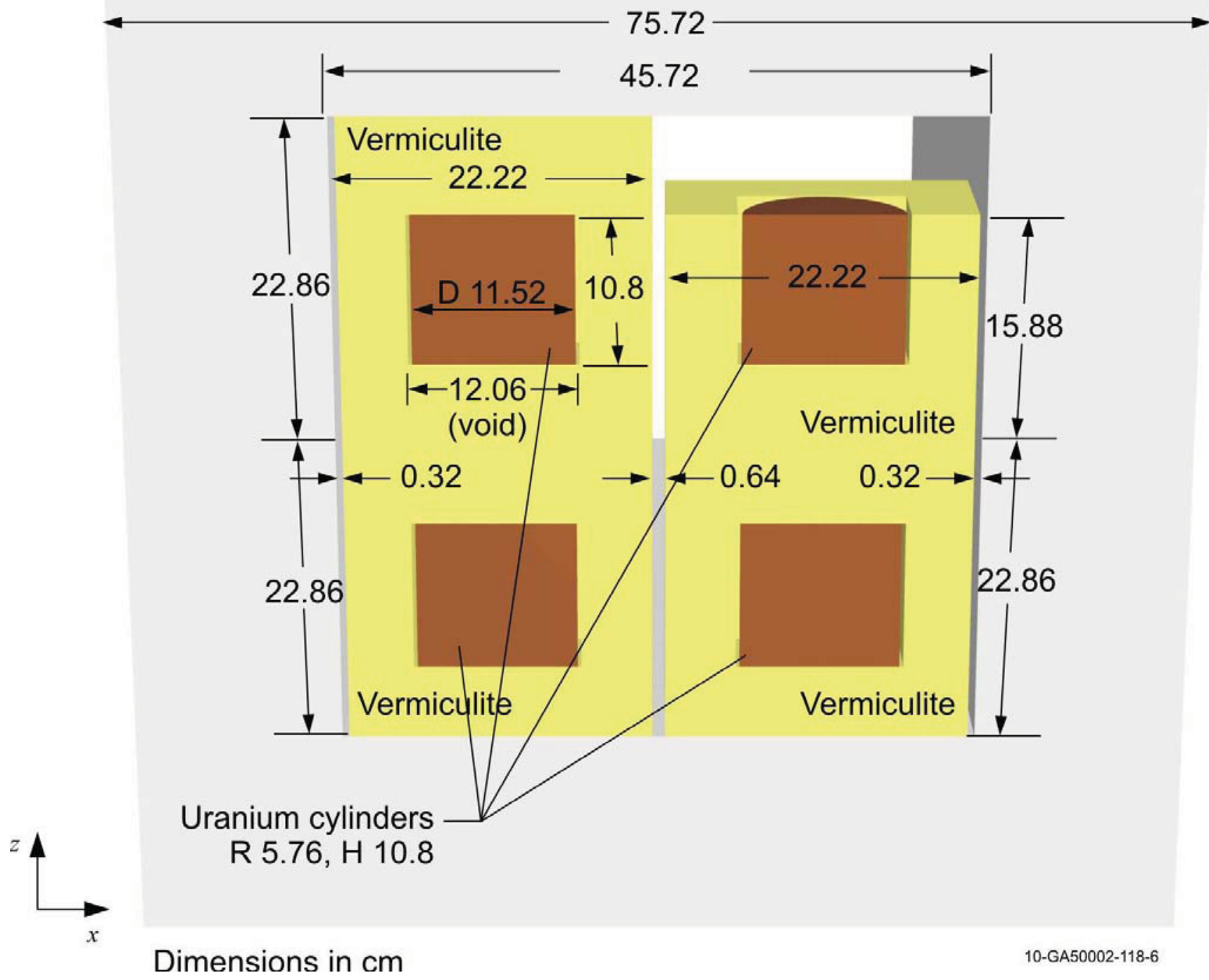

Figure 7. Configuration 21 - Front View. 


\section{HEU-MET-FAST-056}

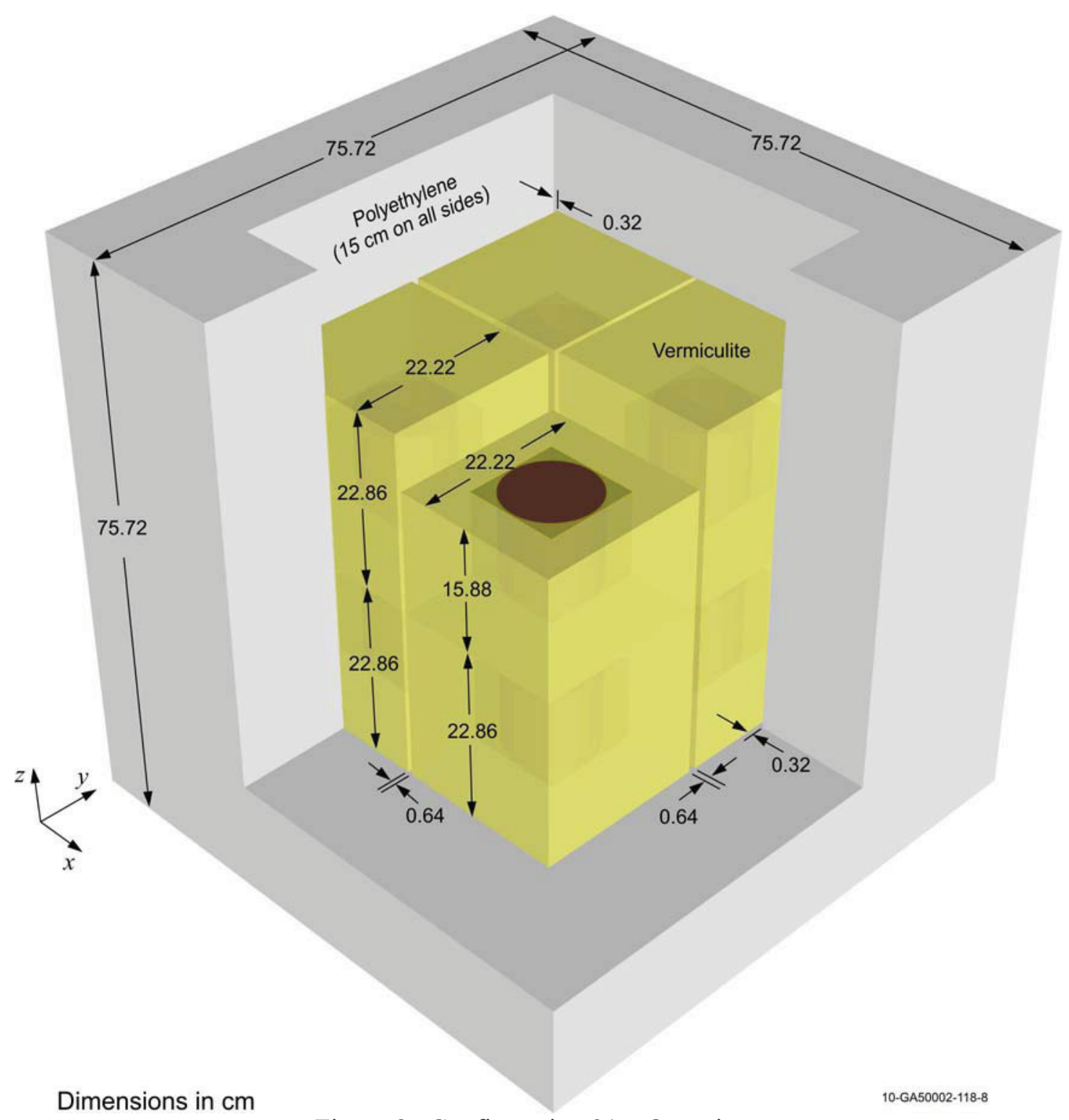

Figure 8. Configuration 21 - Overview.

1.2.5 $\mathbf{k}_{\text {eff }}$ - The experimental report was in some parts comprehensive, but some inconsistencies in the data were found (Ref. 1). The experimental logbook ${ }^{a}$ supplied some additional information, but there was still some information left unclear or not fully explained. Some of the lacking data pertains to the description of the method for determining the experimental $k_{\text {eff }}$ value. The experimental $k_{\text {eff }}$ values appear to be obtained from period measurements, as indicated by the presence of period graphs accompanied by reactivity values in cents. ${ }^{1}$ There is no information regarding the exact method of calculating $\mathrm{k}_{\mathrm{eff}}$ in the

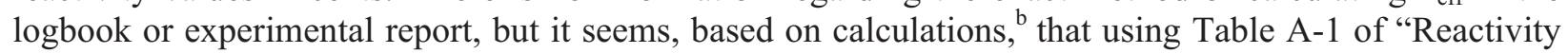
(Cents) versus Asymptotic Period (Seconds) for U235" from Keepin's book entitled Physics of Nuclear Kinetics and a $\beta_{\text {eff }}$ of $0.0064,{ }^{c}$ it is possible to calculate the same reactivity values in cents as those presented in the logbook.

${ }^{a}$ ORNL Critical Experiment Logbook 27r, p 139-181

${ }^{\mathrm{b}}$ Thanks to Virginia Dean who performed these calculations and pointed out their significance.

${ }^{c} 0.0064$ was calculated as the $\beta_{\text {eff }}$ for the experiments of HEU-MET-FAST-054, which was reported in Ref. 1 along with this experiment, and uses the same uranium metal cylinders.

Revision: 0 


\section{NEA/NSC/DOC/(95)03/II \\ Volume II}

HEU-MET-FAST-056

However, there is no data regarding any critical gap widths or methods for extrapolation to closed configuration. There is a gap between the stacks of vermiculite that could reasonably have been the separation between the halves of the tables, but this is not explicitly stated in the logbook or experimental report. The reported $\mathrm{k}_{\mathrm{eff}}$ values for the experiments are in Table 4.

Table 4. Reported $\mathrm{k}_{\mathrm{eff}}$.

\begin{tabular}{|c|c|}
\hline $\begin{array}{c}\text { Experiment } \\
\text { Number }\end{array}$ & Reported $\mathbf{k}_{\text {eff }}$ \\
\hline \hline 18 & 1.0005 \\
\hline 19 & 1.0007 \\
\hline 20 & 1.0016 \\
\hline 21 & 1.0013 \\
\hline
\end{tabular}

\section{$1.3 \quad$ Description of Material Data}

1.3.1 HEU Metal Cylinders - The cylinders used were uranium metal enriched to $93.2 \%$ in ${ }^{235} \mathrm{U}$ (Ref. 1). The eight large cylinder pairs were separated into their top and bottom halves, and each portion was individually measured, with a reported average weight of $20.962 \mathrm{~kg}$ (Ref. 1). This weight, along with the dimensions provided in Table 2, was used by the experimenters to determine the overall density of the cylinders, a reported value of $18.62 \mathrm{~g} / \mathrm{cm}^{3}$ (Ref. 1,3). The reported isotopic composition is listed in Table 5 .

Table 5. Uranium Composition (Ref. 1).

\begin{tabular}{||c|c|}
\hline Isotope & Atom Density $\left(\mathbf{c m}^{\mathbf{3}}\right)$ \\
\hline${ }^{234} \mathrm{U}$ & considered part of ${ }^{238} \mathrm{U}$ \\
\hline${ }^{235} \mathrm{U}$ & $4.448 \mathrm{E}+22$ \\
\hline${ }^{236} \mathrm{U}$ & considered part of ${ }^{238} \mathrm{U}$ \\
\hline${ }^{238} \mathrm{U}$ & $3.201 \mathrm{E}+21$ \\
\hline
\end{tabular}

The experimenter references other works that utilized the same uranium cylinders for different experiments (Ref. 1, 2, 3). These references included a more complete isotopic description, which is included in Table 6.

Table 6. Detailed Uranium Composition (Ref. 2, 3).

\begin{tabular}{||c|c||}
\hline Isotope & Atom Density (atom/barn-cm) \\
\hline \hline${ }^{234} \mathrm{U}$ & $4.7911 \mathrm{E}-04$ \\
\hline${ }^{235} \mathrm{U}$ & $4.4463 \mathrm{E}-02$ \\
\hline${ }^{236} \mathrm{U}$ & $9.5008 \mathrm{E}-05$ \\
\hline${ }^{238} \mathrm{U}$ & $2.6378 \mathrm{E}-03$ \\
\hline
\end{tabular}


HEU-MET-FAST-056

1.3.2 Vermiculite - Following the critical experiments, the vermiculite was weighed and the average density was determined from the measured volume. The vermiculite composition was analyzed using spectroscopy and the results included in the experimental report. It is noted in the report specifically that the results of the analysis do not match those reported by Ricardo Artigas in a paper that analyzed shipping containers for General Electric (Ref. 1, p9). The significance of this comment was not explained; though it is noted elsewhere in the experimental report that the material was also provided by General Electric(Ref. 1, p3, footnote 6) . Chemical spectrograph results are detailed in Table 7. In addition, the logbook provides weight percent analysis for each element, also in Table 7.

Table 7. Vermiculite Spectroscopy Results.

\begin{tabular}{|c|c|c|c|}
\hline Element & $\begin{array}{c}\text { Atom Density } \\
\left(\mathrm{cm}^{-3}\right)\end{array}$ & $\begin{array}{c}\text { Weight } \\
\text { Percent }^{(b)}\end{array}$ & $\begin{array}{c}\text { Weight } \\
\text { Percent }^{(\mathrm{c})}\end{array}$ \\
\hline $\mathrm{H}$ & $5.86 \mathrm{E} 21$ & 3.00 & 2.78 \\
\hline $\mathrm{C}$ & $2.67 \mathrm{E} 21$ & 17.10 & 14.29 \\
\hline $\mathrm{N}$ & $1.77 \mathrm{E} 21$ & 13.50 & 10.81 \\
\hline $\mathrm{O}$ & $6.23 \mathrm{E} 21$ & 45.46 & 52.14 \\
\hline $\mathrm{Mg}$ & $4.0 \mathrm{E} 20$ & 5.27 & 4.25 \\
\hline $\mathrm{Al}$ & $2.5 \mathrm{E} 20$ & 3.78 & 2.25 \\
\hline $\mathrm{Si}$ & $5.8 \mathrm{E} 20$ & 7.86 & 8.03 \\
\hline $\mathrm{Cl}$ & $5.8 \mathrm{E} 18$ & - & - \\
\hline $\mathrm{K}$ & $5.5 \mathrm{E} 19$ & 0.70 & 1.39 \\
\hline $\mathrm{Ca}$ & $2.0 \mathrm{E} 19$ & 0.30 & 0.50 \\
\hline $\mathrm{Ti}$ & 3.4E19 & - & - \\
\hline $\mathrm{Cr}$ & $3.1 \mathrm{E} 18$ & 0.10 & 0.06 \\
\hline $\mathrm{Mn}$ & $1.9 \mathrm{E} 18$ & 0.07 & 0.02 \\
\hline $\mathrm{Fe}$ & $7.86 \mathrm{E} 19$ & 2.86 & 1.30 \\
\hline $\mathrm{Ba}$ & $9.7 \mathrm{E} 18$ & - & - \\
\hline
\end{tabular}

(a) Atom densities can be found in Table 2 of Ref. 1.

(b) Weight percent are calculated on page 173 of the logbook. It is not stated why $\mathrm{Ba}, \mathrm{Ti}$, and $\mathrm{Cl}$ are excluded from the weight percent calculations, because it is known that $\mathrm{NH}_{4} \mathrm{Cl}$ is present in the material.

(c) These weight percents are calculated by hand on p164 of the logbook, and only add to $97.82 \%$, though the experimenter indicates they sum to $98.32 \%$. There is no explanation of this anomaly or reasons for why this analysis does not match reported results.

The logbook provides further information regarding the vermiculite material composition and its measurement. The results were acquired using a semi-quantitative measurement, with a reported associated error "within the range times $1 / 2$ to times 2" according to analysis reports inserted in the logbook. ${ }^{\mathrm{a}}$ There were several handwritten weight percent calculations in this part of the logbook as well, which did not match each other. Results inserted in these pages also indicate that there were impurities, on the order of $84948.620 \mathrm{ppm}$ total. ${ }^{\mathrm{b}}$ However, the data presented in the logbook does not match that in the published experimental report. The most complete and accurate composition data is published in the experimental report.

${ }^{a}$ ORNL Critical Experiments Logbook 27r, between pages 170 and 172

${ }^{\mathrm{b}}$ ORNL Critical Experiments Logbook 27r, p163

Revision: 0

Date: September 30, 2010

Page 13 of 51 


\section{NEA/NSC/DOC/(95)03/II \\ Volume II}

\section{HEU-MET-FAST-056}

The report also contains information regarding the composition of the plyamine in the vermiculite, presented in Table 8. It was described as Reichhold Chemicals resin number 21-015 with a density of $1.117 \mathrm{~g} / \mathrm{cm}^{3}$ (Ref. 1).

Table 8. Plyamine Weight Percent Analysis. ${ }^{\text {(a) }}$

\begin{tabular}{|c|c|}
\hline Element & Weight Percent \\
\hline \hline $\mathrm{H}_{2} \mathrm{O}$ & 20 \\
\hline $\mathrm{H}$ & 6.7 \\
\hline $\mathrm{C} . \mathrm{N}^{2(\mathrm{~b})}$ & 26.3 \\
\hline $\mathrm{O}$ & 28.4 \\
\hline $\mathrm{Na}$ & 0.1 \\
\hline $\mathrm{Cl}$ & 3.1 \\
\hline
\end{tabular}

(a) All elements except the water were referred to being contained in other solids.

(b) The period after the $\mathrm{C}$ is printed in the experimental report, but it may be a typing error.

1.3.3 Polyethylene - No composition information or material density was provided for the polyethylene reflector.

1.3.4 Temperature - No mention of the system temperature was made in the report. A nominal temperature of $293 \mathrm{~K}$ is a reasonable temperature for the Oak Ridge Critical Experimental Facility.

\subsection{Supplemental Experimental Measurements}

No additional supplemental experimental measurements were performed.

${ }^{\text {a }}$ Personal communication between John T. Mihalczo and John D. Bess, February 2010. 
NEA/NSC/DOC/(95)03/II

Volume II

HEU-MET-FAST-056

\subsection{EVALUATION OF THE EXPERIMENTAL DATA}

Monte Carlo N-Particle (MCNP) version 5.1.51 calculations were utilized to estimate the biases and the effects of uncertainties associated with the experimental results in this evaluation. MCNP is a generalpurpose, continuous-energy, generalized-geometry, time-dependent, coupled n-particle Monte Carlo transport code. The Evaluated Neutron Data File library ENDF/B-VII.0 was utilized in analysis of the experiment and benchmark model biases and uncertainties. The total uncertainty for these experiments is considered acceptable, as shown in Table 22 at the end of this section.

\subsection{HEU Cylinder Uncertainties}

It should be noted that the experimenter reported the values for the cylinders with the small holes already homogenized into the cylinders. This simplification in the benchmark model introduced no bias into this evaluation because the experimenter already considered it when reporting the data and results from the experiment.

2.1.1 HEU Cylinder Mass - The average mass of the HEU cylinders of $20.962 \mathrm{~kg}$, with individual masses being presented in Table 1 of Section 1.2.1. No mass deviation was reported in the experimental report or logbook; however, as mentioned previously, these uranium cylinders were used in other experiments and further data was obtained from these sources. In a report published for a different set of experiments, using these same cylinders, an average mass deviation from the mean was reported as $3.4 \mathrm{~g}$ (Ref. 3). However, the given mass in the report was averaged from the individual measured weights of each unit, and confirmed by measuring the mass of an assembled cylinder pair. These mass measurements were reported to vary by as much as 3\%. By using the mass of each individual cylinder found in Table 1, the average deviation from the mean can be calculated as $2.6 \mathrm{~g}$, and the calculated total uncertainty in the HEU mass is $22.0 \mathrm{~g}$. The mass uncertainties are presented in Table 9, and the $1 \sigma$ statistical uncertainty associated with these Monte Carlo calculations is \pm 0.00005 .

Table 9. Uranium Mass Uncertainties.

\begin{tabular}{|c|c|c|}
\hline Case & $\Delta \mathbf{k}_{\text {calc }}$ & $\begin{array}{c}\text { Uncertainty } \\
\left(\Delta \mathbf{k}_{\text {eff }}\right)\end{array}$ \\
\hline \hline 1 & 0.00010 & 0.00010 \\
\hline
\end{tabular}

In the closely related benchmark, HEU-MET-FAST-053, the same HEU cylinders are used in a similarly arranged manner. For this evaluation, the same method of determination of total HEU mass uncertainty has been reproduced, using the equation below. This method is used because the arrangement of the cylinders is not random; in fact, the logbook indicates that special care was taken to assure the cylinder pairs were as uniform as possible. Therefore, the uncertainty cannot be purely random. 
where,

$$
\sigma_{T}=\sqrt{\left(\frac{N}{2}\right)^{2} \sigma_{p h}^{2}+N \sigma_{r}^{2}+N^{2} \sigma_{s}^{2}+N \frac{\sigma_{c}^{2}}{12}}
$$

$N=16$ (the number of HEU pieces whose mass has been measured)

$\sigma_{p h}=2.6 \mathrm{~g}$ (the physics mass uncertainty of the HEU units)

$\sigma_{r}=0.0 \mathrm{~g}$ (the random mass measurement uncertainty)

$\sigma_{s}=0.5 \mathrm{~g}$ (the systematic mass measurement uncertainty)

$\sigma_{c}=1.0 \mathrm{~g}$ (the mass calibration or range uncertainty)

The standard deviation of the reported masses is $2.56 \mathrm{~g}$, which leads to a $1 \sigma$ uncertainty in the density of $0.0023 \mathrm{~g} / \mathrm{cm}^{3}$. The calculated effects the density uncertainty is presented in Table 10, with an associated $1 \sigma$ statistical uncertainty for the Monte Carlo calculation of \pm 0.00005 .

Table 10. Uranium Density Uncertainties.

\begin{tabular}{|c|c|c|}
\hline \hline Case & $\Delta \mathbf{k}_{\text {calc }}$ & $\begin{array}{c}\text { Uncertainty } \\
\left(\Delta \mathbf{k}_{\text {eff }}\right)\end{array}$ \\
\hline \hline 1 & 0.01094 & 0.00193 \\
\hline
\end{tabular}

The calculated uncertainty was scaled using the following equation:

$$
\Delta k_{e f f}=\frac{\Delta k_{c a l c}}{\sqrt{8}}
$$

The uncertainty was divided by the square root of eight because there are eight cylinder pairs in the experimental array.

2.1.2 Placement and Spatial Variation of HEU Cylinders - The experimenter notes that care was taken to assure consistent placement of the uranium cylinders. However, the measurements for the experimental configurations are referred to as averages, and said to be accurate to within $\pm 0.06 \mathrm{~cm}$ (Ref. 1). This value would typically be interpreted as bounding; however, because of the lack of information on exactly how it was achieved and the added uncertainty associated with the placement of the vermiculite sheets it is treated as a $1 \sigma$ value.

The sensitivity of the benchmark to the spatial variation of the uranium cylinders is quite high. This is believed to be because the experiment is sensitive to the amount of reflection from the vermiculite and the proximity of the uranium cylinders to the vermiculite sheets. Table 11 shows the sensitivity calculated for the uranium cylinder spatial variation by varying the pitch of each cylinder $+0.06 \mathrm{~cm}$ from its three neighbors, with a $1 \sigma$ statistical uncertainty associated with the Monte Carlo calculations of \pm 0.00005

Table 11. Uranium Placement Uncertainties.

\begin{tabular}{|c|c|c|}
\hline Case & $\Delta \mathbf{k}_{\text {calc }}$ & $\begin{array}{c}\text { Uncertainty } \\
\left(\Delta \mathbf{k}_{\text {eff }}\right)\end{array}$ \\
\hline \hline 1 & 0.00027 & 0.00027 \\
\hline
\end{tabular}


2.1.3 HEU Isotopic Content - The eight large cylinder pairs were reported to be $93.2 \%$ enriched uranium metal. The $\mathrm{U}^{234}$ and $\mathrm{U}^{236}$ content were reported (Ref. 1) to be included in the $\mathrm{U}^{238}$ content. The reported atom densities are listed in Table 4 of the previous section. No details were provided regarding impurities contained in the uranium.

As mentioned previously, these fissile units have been used in other experiments, and the weight percents for $U^{234}, U^{235}, U^{236}$, and $U^{238}$ were presented in further detail in other related reports (Ref. 2); from these values, a more complete isotopic composition was obtained.

The detailed weight percents and calculated atom densities from Ref. 2 are provided in Table 6, and these values were used to derive models of this experiment. The values found in Table 6 were referenced by D. W. Magnuson as the source of the values from Table 5. For all calculations in this report the detailed isotopic composition was used.

The reported enrichment data was given with no uncertainty. However, the first reported use of these cylinders was in the Tinker Toy experiments, which were evaluated in HEU-MET-FAST-026, where half of the least significant digit $(0.05 \mathrm{wt} . \%)$ was used as the $1 \sigma$ uncertainty. Other related benchmarks (HEU-MET-FAST-053) also used this value. Uncertainty values of 0.04 to $0.1 \mathrm{wt} . \%$ are also consistent with measurement capabilities at the time of these experiments. The change in $\mathrm{k}_{\mathrm{eff}}$ caused by isotopic uncertainty of ${ }^{235} \mathrm{U}$ was determined by increasing or decreasing the ${ }^{235} \mathrm{U}$ isotopic concentration by 1 wt.\% $(20 \times 0.05 \%)$ while keeping the overall uranium density constant. These results are summarized in Table 12 , with a $1 \sigma$ statistical uncertainty in the Monte Carlo calculations of \pm 0.00005 .

Table 12. Uranium Composition Uncertainty.

\begin{tabular}{|c|c|c|}
\hline Case & $\Delta \mathbf{K}_{\text {calc }}$ & $\begin{array}{c}\text { Uncertainty } \\
\left(\Delta \mathbf{k}_{\text {eff }}\right)\end{array}$ \\
\hline \hline 1 & 0.00767 & 0.00038 \\
\hline
\end{tabular}

To obtain the uncertainty, the following formula was used because the composition was evaluated as a $1 \sigma$ uncertainty, as suggested by other similar benchmarks.

$$
\Delta k_{e f f}=\frac{\Delta k_{\text {calc }}}{20}
$$

2.1.4 Cylinder Dimensions - The average radius and height were reported as $5.76 \mathrm{~cm}$ and $10.80 \mathrm{~cm}$ respectively. No associated uncertainty was given in this report; however, the same cylinders were used in experiments evaluated in HEU-MET-FAST-023, where the dimensions were reported to be machined to within $\pm 0.003 \mathrm{~cm}$ in height and $1.5 \%$ in diameter. This is assumed to be a $3 \sigma$ value, since it is a machining tolerance.

Both the radius and height of all eight cylinders were adjusted simultaneously. The statistical uncertainty associated with the Monte Carlo calculation was \pm 0.00019 , and the results are presented in Table 13. The effective uncertainty was obtained by taking half of the difference between the calculated effect of increasing and then decreasing all cylinder dimensions. Mass was conserved by adjusting the density of the uranium. 
NEA/NSC/DOC/(95)03/II

Volume II

HEU-MET-FAST-056

Table 13. Uranium Dimensional Uncertainties.

\begin{tabular}{|c|c|c|}
\hline Case & $\Delta \mathbf{k}_{\text {calc }}$ & $\begin{array}{c}\text { Uncertainty } \\
\boldsymbol{\Delta} \mathbf{k}_{\text {eff }}\end{array}$ \\
\hline \hline 1 & 0.00426 & 0.00050 \\
\hline
\end{tabular}

The total dimensional uncertainties in the uranium were calculated using the following equation, adjusting for the eight cylinder pairs and the $3 \sigma$ machining tolerances:

$$
\Delta k_{e f f}=\frac{\Delta k_{\text {calc }}}{3 \sqrt{8}}
$$

The uncertainty was divided by the square root of eight because there are eight cylinder pairs in the experimental array. Eight is used rather than 16 because the experimenter noted that special care was taken to match cylinders into pairs that were as similar as possible, and this must be taken into account when determining uncertainty.

\subsection{Vermiculite Uncertainties}

2.2.1 Vermiculite Composition - The logbook contained laboratory report documents from the spectrographic analysis of the plyamine-bonded vermiculite. It indicated that a semi-quantitative analysis method was used, and the "actual values" of the composition "should be within the range times $1 / 2$ to times 2." "The logbook contained this one data sheet with results of the composition analysis. The analysis was referred to as "semi-quantitative" and indicated that the range for this analysis was typical for this type. The uncertainty was calculated by increasing and decreasing the atom densities of the vermiculite by a factor of 0.5 and 2 , respectively. This is assumed to be bounding with a uniform probability distribution.

In addition to the spectrographic analysis reports, several weight percent calculations and results of multiple analyses are presented in the logbook between pages 202 and 207 that did not match the published values, or each other. Some values were close, and it is assumed that the experimenter made certain judgment calls concerning what elements were most important in the report. Published data are used whenever there are inconsistencies.

Based on the uncertainty analysis the effects of uncertainty in the vermiculite composition are minimal, as presented in Table 14. All data in Table 14 were calculated with a $1 \sigma$ Monte Carlo statistical uncertainty of \pm 0.00017 . The effective uncertainty was obtained by taking half of the difference between the calculated effect of increasing and then decreasing the quantities of vermiculite constituents.

Table 14. Vermiculite Composition Uncertainties.

\begin{tabular}{|c|c|c|}
\hline Case & $\Delta \mathbf{k}_{\text {calc }}$ & $\begin{array}{c}\text { Uncertainty } \\
\boldsymbol{\Delta} \mathbf{k}_{\text {eff }}\end{array}$ \\
\hline \hline 1 & 0.00225 & 0.00129 \\
\hline
\end{tabular}

${ }^{a}$ ORNL Critical Experiments Logbook 27r, p 170. 
The total uncertainty in the vermiculite composition was calculated using the following equation, as the uncertainty was assumed to be bounding and random.

$$
\Delta k_{e f f}=\frac{\Delta k_{c a l c}}{\sqrt{3}}
$$

2.2.2 Vermiculite Impurities - Impurity data for the vermiculite were provided in the experimental logbook; however, these data were incomplete and the analysis used to produce the published list of constituents is not explained. A list of possible impurities and their concentration in parts per million $(\mathrm{ppm})$ are listed in Appendix B. In the experimental report, the elements $\mathrm{Ti}$ and $\mathrm{Ba}$ were ignored as impurities (Ref. 1). However, there are atom densities provided for these elements in the vermiculite analysis in the experimental report. Titanium had the highest concentration, at $14000.0 \mathrm{ppm}$ $\left(3.4 \mathrm{E} 19 \mathrm{~cm}^{-3}\right)$. All other impurities in the analysis in Appendix B are far below this value, except Fe, which is considered a constituent in the experimental report. To evaluate the effect of impurities on the experiment, calculations were performed with and without $\mathrm{Ti}$ and $\mathrm{Ba}$. The impurity results were scaled by the following equation, where the square root of three is used because the uncertainty is assumed to be bounding and equally probable.

$$
\Delta k_{\text {eff }}=\frac{\Delta k_{\text {calc }}}{\sqrt{3}}
$$

The results can be seen in Table 15. The $1 \sigma$ uncertainty associated with the Monte Carlo calculation is 0.00005 .

Table 15. Vermiculite Impurity Uncertainties.

\begin{tabular}{|c|c|c|}
\hline Case & $\boldsymbol{\Delta} \mathbf{k}_{\text {calc }}$ & $\begin{array}{c}\text { Uncertainty } \\
\boldsymbol{\Delta} \mathbf{k}_{\text {eff }}\end{array}$ \\
\hline \hline 1 & 0.0027 & 0.0016 \\
\hline
\end{tabular}

2.2.3 Vermiculite Dimensions - The vermiculite sheets were described as being very friable and uneven. Additionally, the original pieces arrived in the wrong dimensions and were hand cut, which further added to the roughness of the vermiculite sheets (Ref. 1). The experimental report indicated that the vermiculite dimensions were known to within $\pm 0.2 \mathrm{~cm}$ (Ref. 1). This value would typically be interpreted as bounding; however, because of the sheets were described as friable, uneven, and hand cut it is treated as a $1 \sigma$ value. The dimensions in all directions were reduced simultaneously and then increased simultaneously to determine the effect of the vermiculite dimensional uncertainty. While these adjustments were made, all spacing between vermiculite and uranium pieces was maintained at a constant distance to avoid effects from changes in reflection influencing the results. The results are presented in Table 16. The results in Table 16 were calculated with a Monte Carlo $1 \sigma$ statistical uncertainty of \pm 0.00017 . The effective uncertainty was obtained by taking half of the difference between the calculated effect of increasing and then decreasing the dimensions of the vermiculite.

Table 16. Vermiculite Dimensional Uncertainties.

\begin{tabular}{|c|c|c|}
\hline Case & $\Delta \mathbf{k}_{\text {calc }}$ & $\begin{array}{c}\text { Uncertainty } \\
\boldsymbol{\Delta} \mathbf{k}_{\text {eff }}\end{array}$ \\
\hline \hline 1 & 0.00064 & 0.00064 \\
\hline
\end{tabular}


This uncertainty is treated as $100 \%$ systematic because of the very poor condition of the vermiculite.

2.2.4 Vermiculite Density - No uncertainty information was provided for the density of the vermiculite separating sheets. The provided density was $0.34 \mathrm{~g} / \mathrm{cm}^{3}$. To evaluate the effect of the density on the experiment, half of the last significant digit was used to vary the density. The results were negligible, before using any scaling.

2.2.5 Vermiculite Gaps - It is possible that the vermiculite stacks are split in both the $\mathrm{x}$ and $\mathrm{y}$ direction, or only in the $\mathrm{x}$ direction. The uncertainty from not knowing whether there is a gap in the $\mathrm{y}$ direction was calculated by modeling equal gaps in the $\mathrm{x}$ and $\mathrm{y}$ direction and comparing that to a model of only an x direction gap. This represents a $1 \sigma$ uncertainty, as shown in Table 17.

Table 17. Vermiculite Gap Uncertainties.

\begin{tabular}{|c|c|c||}
\hline Case & $\boldsymbol{\Delta} \mathbf{k}_{\text {calc }}$ & $\begin{array}{c}\text { Uncertainty } \\
\boldsymbol{\Delta} \mathbf{k}_{\text {eff }}\end{array}$ \\
\hline \hline 1 & -0.00315 & 0.00315 \\
\hline
\end{tabular}

\subsection{Uncertainties in the Reflector}

2.3.1 Reflector Composition and Impurities - Composition data were not available for the polyethylene reflector. Therefore, the material was represented as only the elemental atomic concentrations of the elements $\mathrm{C}$ and $\mathrm{H}$; no impurities were mentioned. However, experiment performed in the same facility, using the same metal cylinders, used the polyethylene described in Table 18 (Ref. 3).

Table 18. Polyethylene Atom Densities $\left(0.92 \mathrm{~g} / \mathrm{cm}^{3}\right)$.

\begin{tabular}{|c|c|}
\hline Element & $\begin{array}{c}\text { Atom Density } \\
\text { (atoms/b-cm) }\end{array}$ \\
\hline \hline $\mathrm{H}$ & $7.90 \mathrm{E}-02$ \\
\hline $\mathrm{C}$ & $3.95 \mathrm{E}-02$ \\
\hline
\end{tabular}

However, an evaluation of this experiment (HEU-MET-FAST-053) stated that "the atomic density in Reference 1 is presented as $7.90 \mathrm{E}-03$ atoms/b-cm, which would lead to a chemical formula of $\mathrm{HC}_{5}{ }^{a}$. The density is anticipated to be higher by exactly a factor of 10.0." The density used for that evaluation was $0.92 \mathrm{~g} / \mathrm{cm}^{3}$.

HEU-MET-THERM-033 contains an analysis of the uncertainty associated with the effects of impurities in polyethylene from Los Alamos National Laboratory. This report concluded the total uncertainty in the reflector composition was \pm 0.0008 . These experiments did not use the same material; however the impurity information from HEU-MET-THERM-033 was used to estimate of the effects of possible impurities in polyethylene. The effects of this uncertainty are shown in Table 19.

\footnotetext{
${ }^{\text {a }}$ Polyethylene is typically $\mathrm{CH}_{2}$ 
NEA/NSC/DOC/(95)03/II

Volume II

HEU-MET-FAST-056

Table 19. Polyethylene Impurities.

\begin{tabular}{|c|c|c|}
\hline Case & $\Delta \mathbf{k}_{\text {calc }}$ & $\Delta \mathbf{k}_{\text {eff }}$ \\
\hline \hline 1 & 0.00364 & 0.00210 \\
\hline
\end{tabular}

2.3.2 Thickness of the Reflector - The experimental report indicates that the polyethylene reflector was $15 \mathrm{~cm}$ on each side. However, in a footnote to Table 1, the experimenter reports that the reflector was in fact " $15.24 \mathrm{~cm}$ or greater", except on two sides where it was $14.60 \mathrm{~cm}$. However, no logbook sketches or diagrams showed these dimensions, and it was nowhere indicated which sides were thicker. The effects of uncertainty in reflector thickness were estimated by increasing all sides to $15.24 \mathrm{~cm}$ and then subsequently decreasing all sides to $14.60 \mathrm{~cm}$. The benchmark model incorporates a square reflector that is $15 \mathrm{~cm}$ on a side, and the results indicate that the uncertainty in the polyethylene reflector dimensions do not significantly affect the benchmark $\mathrm{k}_{\text {eff }}$ values. The results of the analysis were calculated with a $1 \sigma$ Monte Carlo statistical uncertainty of 0.00017 for each perturbation calculation conducted. The calculated results presented in Table 20 were obtained by taking half of the difference between the calculated effect of increasing and then decreasing the dimensions of the polyethylene.

Table 20. Polyethylene Dimensions Uncertainties.

\begin{tabular}{|c|c|c|}
\hline Case & $\Delta \mathbf{k}_{\text {calc }}$ & $\begin{array}{c}\text { Uncertainty } \\
\boldsymbol{\Delta} \mathbf{k}_{\text {eff }}\end{array}$ \\
\hline \hline 1 & 0.00008 & insignificant \\
\hline
\end{tabular}

The total dimensional uncertainties in the polyethylene were calculated using the following equation:

$$
\Delta k_{\text {eff }}=\frac{\Delta k_{\text {calc }}}{\sqrt{(6-2)}}
$$

The scaling factor of $\sqrt{ } 4$ is used because there are six sides of the reflector, but two of the six sides are known not to change.

2.3.3 Polyethylene Density - There was no density or composition information in the experimental report or logbook pertaining to the polyethylene. However, commercial polyethylene has a limited range of densities, depending on the type: $0.880 \mathrm{~g} / \mathrm{cm}^{3}$ for low density polyethylene ${ }^{\mathrm{a}}$ to $0.97 \mathrm{~g} / \mathrm{cm}^{3}$ for ultra high molecular weight polyethylene. ${ }^{\mathrm{b}}$ The uncertainty in the density of the polyethylene was evaluated by taking the maximum variation and comparing the change in $\mathrm{k}_{\mathrm{eff}}$. This assures that the uncertainty is bounded by the available information. The results are presented in Table 21, and had a $1 \sigma$ Monte Carlo statistical uncertainty of \pm 0.00016 .

\footnotetext{
${ }^{a}$ Density information found in fact sheets available from Mitsui Chemicals America, Inc. http://www.mitsuichemicals.com. Accessed September 2009.

${ }^{\mathrm{b}}$ Density information available for product information from the Dow Chemical Company. http://www.dow.com/elastomers/products/vldpe.html. Accessed August 2009.

Revision: 0

Date: September 30, 2010

Page 21 of 51
} 
NEA/NSC/DOC/(95)03/II

Volume II

HEU-MET-FAST-056

Table 21. Polyethylene Density Uncertainties.

\begin{tabular}{|c|c|c|}
\hline Case & $\Delta \mathbf{k}_{\text {calc }}$ & $\begin{array}{c}\text { Uncertainty } \\
\boldsymbol{\Delta} \mathbf{k}_{\text {eff }}\end{array}$ \\
\hline \hline 1 & 0.00951 & 0.00275 \\
\hline
\end{tabular}

The total effect of uncertainty in the polyethylene density was calculated using the following equation, because the uncertainty is treated as a one-sided right-triangular bounding uncertainty:

$$
\Delta k_{e f f}=\frac{\Delta k_{c a l c}}{\sqrt{12}}
$$

This is treated as a one sided triangular uncertainty because at the time the experiment was performed, most polyethylene products were produced with densities in the higher ranges; technology was not developed to produce some of the lower density polyethylene types. ${ }^{a}$ It is more probable that the polyethylene was a higher density than lower, and the uncertainty is bound by the density range of 0.880 $\mathrm{g} / \mathrm{cm}^{3}$ to $0.92 \mathrm{~g} / \mathrm{cm}^{3}$ (as the Ultra High Density PPE was also not commonly used at this time period). ${ }^{\mathrm{b}}$

\subsection{Uncertainty in the Experimental Determination of $\mathbf{k}_{\text {eff }}$}

There is no data available regarding the method of determining the critical gap in the split table apparatus, nor is there sufficient information to determine uncertainty in extrapolation to $k_{\text {eff }}$ for the experimental $k_{\text {eff }}$ values. To deal with this uncertainty, only one of the experimental configurations was evaluated as a benchmark experiment and the others used to demonstrate reproducibility, variability in the amount of Vermiculite, uncertainty in extrapolation of $\mathrm{k}_{\mathrm{eff}}$ to the gapless configuration.

The reason for treating only one case as a benchmark is because the only difference from one case to the next is a small variation in the amount of Vermiculite and the experiments are not very sensitive to these permutations. The other 3 experiments were evaluated to provide an uncertainty in the inferred $k_{\text {eff }}$ value. It is understood that these are four separate experiments; however, they are not very sensitive to the only reported parameter that changes between the configurations (the vermiculite stack height). This makes it reasonable to use these other experiments to estimate uncertainty in the reported experimental $\mathrm{k}_{\mathrm{eff}}$ value.

Experiment 18 is the reference configuration. This case was chosen because the closed configuration had an experimental $\mathrm{k}_{\text {eff }}$ closest to unity. Table 4 (Section 1.2.5) lists each experimental number and its corresponding experimental $k_{\text {eff. }}$ This table is reproduced below as Table 22 for convenience.

Table 22. Reported $\mathrm{k}_{\mathrm{eff}}$ Values.

\begin{tabular}{||c|c||}
\hline $\begin{array}{c}\text { Experiment } \\
\text { Number }\end{array}$ & Reported $\mathbf{k}_{\text {eff }}$ \\
\hline \hline 18 & 1.0005 \\
\hline 19 & 1.0007 \\
\hline 20 & 1.0016 \\
\hline 21 & 1.0013 \\
\hline
\end{tabular}

\footnotetext{
${ }^{\text {a }}$ Private communication with John Gallager, WR Grace Company. June 2010.

${ }^{\mathrm{b}}$ Private communication with John Gallager, WR Grace Company. June 2010. 


\section{NEA/NSC/DOC/(95)03/II \\ Volume II}

\section{HEU-MET-FAST-056}

The standard deviation in the $k_{\text {eff }}$ measurements is \pm 0.0005 , which is treated as a $1 \sigma$ uncertainty and represents the uncertainty in the $\mathrm{k}_{\text {eff }}$ extrapolation from a critical condition with an unspecified gap width to a closed position, and also accounts for experiment repeatability. Similar experiments (HEU-MET-FAST-053) were found to have a similar $1 \sigma$ uncertainty of 0.0003 .

\section{$2.5 \quad$ Total Experimental Uncertainty}

The total uncertainty for the experiment was calculated by taking the square root of the sum of the squares of all the individual uncertainties discussed in this section. The summarized total uncertainties for each case are presented in Table 23. A negligible value is less than 0.00005 . The total uncertainty was calculated as the square root of the sum of the squares of the individual uncertainties.

Table 23. Total Experimental Uncertainty.

\begin{tabular}{||l|c|}
\hline \multicolumn{1}{|c|}{ Uncertainty Parameter } & $\Delta \mathbf{k}_{\text {eff }}$ \\
\hline \hline Uranium Mass & negligible \\
\hline Uranium Density & 0.00193 \\
\hline Uranium Placement & 0.00027 \\
\hline Uranium Content & 0.00038 \\
\hline Uranium Dimensions & 0.0005 \\
\hline Vermiculite Composition & 0.00129 \\
\hline Vermiculite Impurities & 0.0016 \\
\hline Vermiculite Dimensions & 0.00064 \\
\hline Vermiculite Gap & 0.00315 \\
\hline Vermiculite Density & negligible \\
\hline Polyethylene Impurities & 0.0021 \\
\hline Polyethylene Dimensions & negligible \\
\hline Polyethylene Density & 0.00275 \\
\hline Total Uncertainty & 0.0055 \\
\hline \hline
\end{tabular}


NEA/NSC/DOC/(95)03/II

Volume II

HEU-MET-FAST-056

\subsection{BENCHMARK SPECIFICATIONS}

\subsection{Description of Model}

Experiment 18 was performed using a split table apparatus, which had a small, unspecified gap between the two halves of the table. Information on the other three experiments is provided in Appendix C.

3.1.1 Uranium Simplifications - The uranium cylinders were modeled without the support holes running through them. The density was unchanged because calculations showed that the experimenter had already accounted for the homogenization of the cylinders to disperse the holes into the whole body of the cylinders. This simplification was essentially already accounted for when the experimenter published his data, and no bias was created when using this simplification in the benchmark model.

Additionally, the uranium cylinders are modeled as one piece, instead of the cylinder pairs that were used. The effect of this simplification is negligible.

3.1.2 Reflector Gaps - Gaps between the blocks in the reflector are neglected, and the reflector is modeled as one solid mass. The effect of this simplification is assumed negligible.

3.1.3 Vermiculite Gaps - The gaps between the cells of vermiculite are preserved, but the rough edges are assumed to be even. The effect of this simplification is negligible.

3.1.4 Room Return - Because of the thick polyethylene reflector, room return effects are assumed to be negligible.

\subsection{Model Dimensions}

3.2.1 HEU Metal Cylinders - Eight 10.8-cm tall, highly enriched uranium (HEU) metal cylinders with an outside diameter of $11.52 \mathrm{~cm}$ and a mass of $20.962 \mathrm{~kg}$ were stacked in a $2 \times 2 \times 2$ array with interstitial vermiculite material as shown in Figures 9 and 10.

3.2.2 Vermiculite Blocks - Plyamine-bonded vermiculite surrounds the HEU cylinders for each cell of the array. See Table 23 and Figures 9 and 10 for dimensions.

3.2.3 Polyethylene Reflector - A 15-cm-thick polyethylene reflector is position on all sides, top and bottom.

3.2.4 Assembly Description - The dimensions of the vermiculite are detailed in Table 23.

Table 23. Vermiculite Dimensions.

\begin{tabular}{|c|c|c|c|c|}
\hline Case & $\begin{array}{c}\text { Experiment } \\
\text { Number }\end{array}$ & X Dimension (cm) & Y Dimension (cm) & Z Dimension (cm) \\
\hline \hline 1 & 18 & Inner: 12.06 & Inner: 12.06 & Inner: 10.8 \\
& & Outer: 22.22 & Outer: 22.22 & Outer: 22.86 \\
\hline
\end{tabular}

See Figures 9 and 10, below, for further clarification of Table 23. Each cell is described by the uranium cylinder, the surrounding vermiculite, and the associated gap between the cylinder and the vermiculite. Case 1 was a base configuration with all eight cells having the same dimensions. 
NEA/NSC/DOC/(95)03/II

Volume II

HEU-MET-FAST-056

Polyethylene ( $15 \mathrm{~cm}$ on all sides)

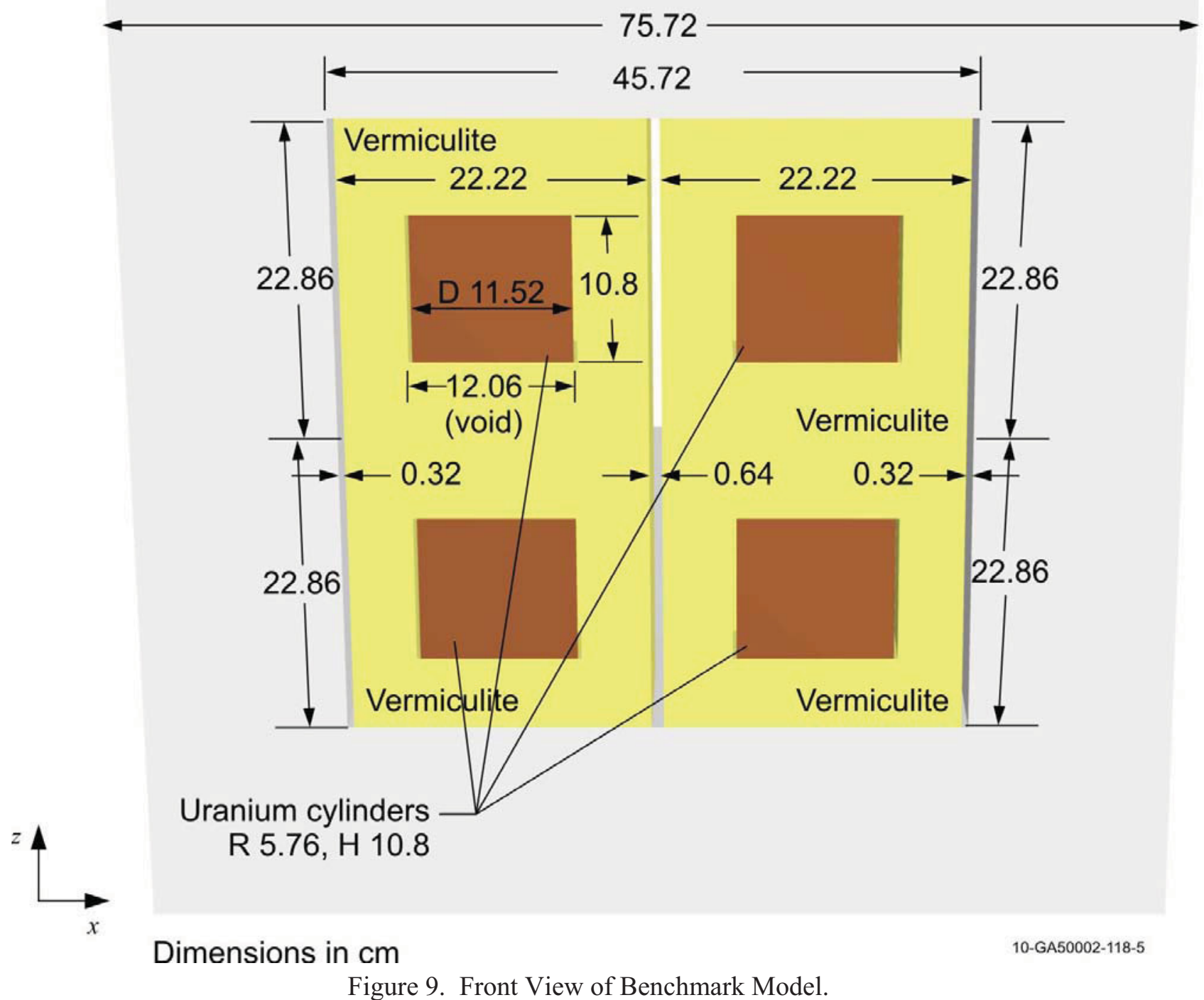

Figure 9. Front View of Benchmark Model. 


\section{NEA/NSC/DOC/(95)03/II \\ Volume II}

\section{HEU-MET-FAST-056}

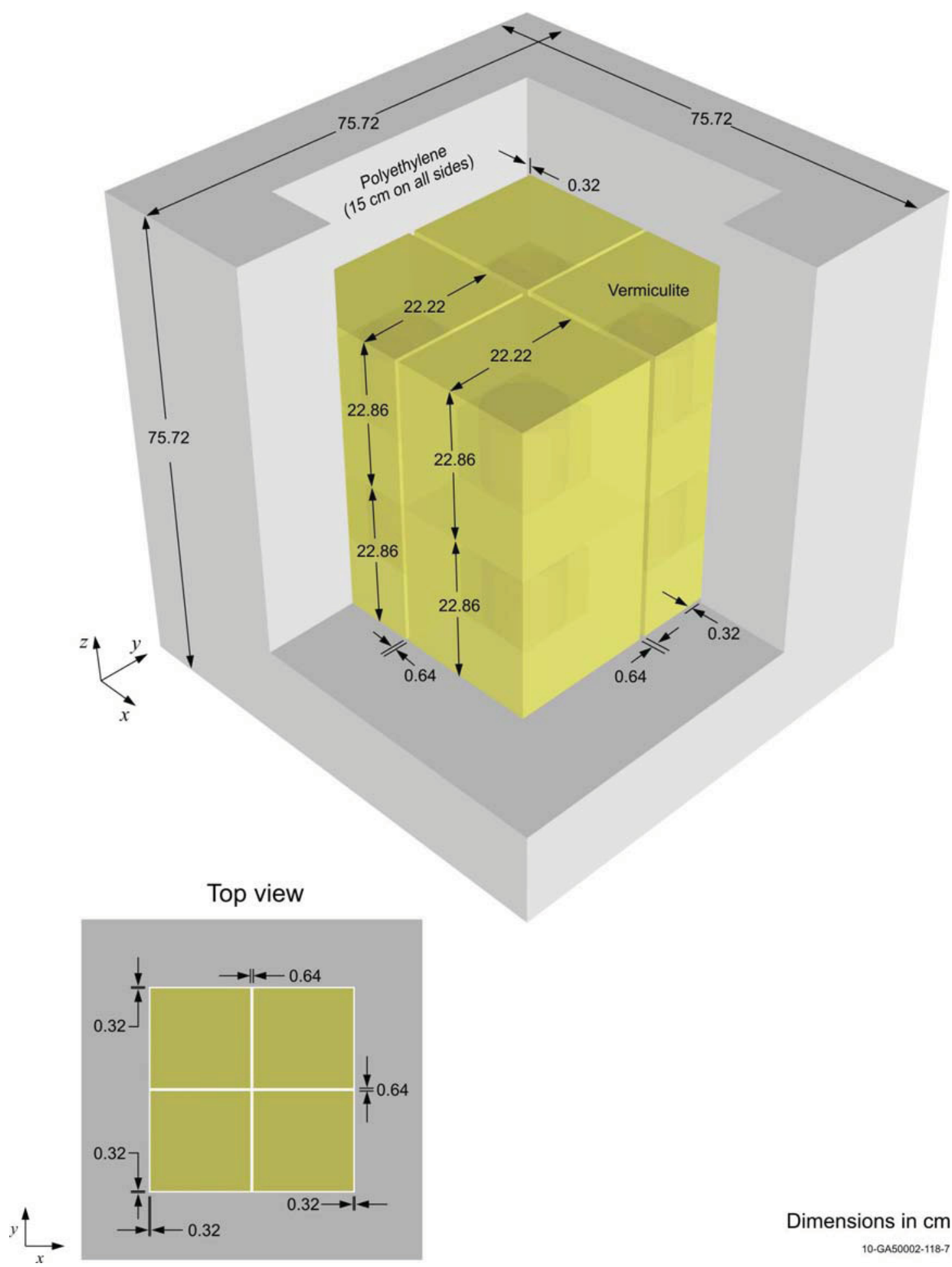

Figure 10. Overview of Benchmark Model. 
HEU-MET-FAST-056

\subsection{Description of Material Data}

3.3.1 HEU Metal Cylinders - The cylinders used were uranium metal enriched to $93.2 \%$ in ${ }^{235} \mathrm{U}$ with an average weight of $20.962 \mathrm{~kg}$ and mass density of $18.62 \mathrm{~g} / \mathrm{cm}^{3}$. The reported isotopic composition is listed in Table 24.

Table 24. Uranium Composition.

\begin{tabular}{|c|c|}
\hline Isotope & $\begin{array}{c}\text { Atom Density } \\
\text { (atoms/b-cm) }\end{array}$ \\
\hline \hline${ }^{234} \mathrm{U}$ & $4.7911 \mathrm{E}-04$ \\
\hline${ }^{235} \mathrm{U}$ & $4.4463 \mathrm{E}-02$ \\
\hline${ }^{236} \mathrm{U}$ & $9.5008 \mathrm{E}-05$ \\
\hline${ }^{238} \mathrm{U}$ & $2.6378 \mathrm{E}-03$ \\
\hline
\end{tabular}

3.3.2 Vermiculite - The vermiculite composition is given in Table 25. There were several analysis results provided in the logbook, but this report uses only the information available in the published experimental report, which does not include impurities.

Table 25. Vermiculite Composition.

\begin{tabular}{|c|c|}
\hline Element & $\begin{array}{c}\text { Atom Density } \\
\text { (atoms/b-cm) }\end{array}$ \\
\hline $\mathrm{H}$ & $5.86 \mathrm{E}-03$ \\
\hline $\mathrm{C}$ & $2.67 \mathrm{E}-03$ \\
\hline $\mathrm{N}$ & $1.77 \mathrm{E}-03$ \\
\hline $\mathrm{O}$ & $6.23 \mathrm{E}-03$ \\
\hline $\mathrm{Mg}$ & $4.00 \mathrm{E}-04$ \\
\hline $\mathrm{Al}$ & $2.50 \mathrm{E}-04$ \\
\hline $\mathrm{Si}$ & $5.80 \mathrm{E}-04$ \\
\hline $\mathrm{Cl}$ & $5.80 \mathrm{E}-06$ \\
\hline $\mathrm{K}$ & $5.50 \mathrm{E}-05$ \\
\hline $\mathrm{Ca}$ & $2.00 \mathrm{E}-05$ \\
\hline $\mathrm{Ti}$ & $3.40 \mathrm{E}-05$ \\
\hline $\mathrm{Cr}$ & $3.10 \mathrm{E}-06$ \\
\hline $\mathrm{Mn}$ & $1.90 \mathrm{E}-06$ \\
\hline $\mathrm{Fe}$ & $7.86 \mathrm{E}-05$ \\
\hline $\mathrm{Ba}$ & $9.70 \mathrm{E}-06$ \\
\hline
\end{tabular}

3.3.3 Polyethylene - Composition data were not provided, but an experiment performed in the same facility, using the same metal cylinders, used the polyethylene described in Table 24 (Ref. 3). The composition of the polyethylene is given in Table 26. 


\section{NEA/NSC/DOC/(95)03/II \\ Volume II \\ HEU-MET-FAST-056}

Table 26. Polyethylene Atom Densities $\left(0.92 \mathrm{~g} / \mathrm{cm}^{3}\right)$.

\begin{tabular}{|c|c|}
\hline Element & $\begin{array}{c}\text { Atom Density } \\
\text { (atoms/b-cm) }\end{array}$ \\
\hline \hline $\mathrm{H}$ & $7.90 \mathrm{E}-02$ \\
\hline $\mathrm{C}$ & $3.95 \mathrm{E}-02$ \\
\hline
\end{tabular}

\subsection{Temperature Data}

The benchmark models are at room temperature (293 K).

\subsection{Experimental and Benchmark Model $\mathbf{k}_{\text {eff }}$}

The experimental and benchmark model $\mathrm{k}_{\mathrm{eff}}$ values are presented in Table 27 together with their uncertainties, as described in Section 2.0.

Table 27. Experiment and Benchmark-Model $k_{\text {eff }}$ Values and Uncertainties $(1 \sigma)$.

\begin{tabular}{|c|c|c|}
\hline Case & $\begin{array}{c}\text { Experimental } \\
\mathbf{k}_{\text {eff }}\end{array}$ & Benchmark $\mathbf{k}_{\text {eff }}$ \\
\hline \hline 1 & $1.0005 \pm 0.0055$ & $1.0005 \pm 0.0055$ \\
\hline
\end{tabular}


NEA/NSC/DOC/(95)03/II
Volume II

HEU-MET-FAST-056

\subsection{RESULTS OF SAMPLE CALCULATIONS}

Results were calculated using MCNP5 and ENDF/B-VII neutron cross section libraries with the input decks and specifications provided in Appendix A. The vermiculite was modified using the thermal scattering $\mathrm{S}(\alpha, \beta)$ cross-section data for polyethylene, because there was no cross-section data for plyamine. The $\mathrm{C}$ and $\mathrm{H}$ atoms interact in plyamine as in polyethylene, and were modified in this way to improve the accuracy of the calculation.

It should be noted that the calculated $k_{\text {eff }}$ values vary from the benchmark values within the $1 \sigma$ uncertainty.

Table 28. Sample Calculation Results.

\begin{tabular}{|c|c|c|c||}
\hline Case & Benchmark $\mathbf{k}_{\text {eff }}$ & $\begin{array}{c}\text { MCNP5 } \\
\text { (Continuous Energy } \\
\text { ENDF/B-VII.0) }\end{array}$ & $\frac{C-E}{E} \%$ \\
\hline \hline 1 & $1.0005 \pm 0.0055$ & $1.0106 \pm 0.00005$ & 1.01 \\
\hline
\end{tabular}


NEA/NSC/DOC/(95)03/II
Volume II

HEU-MET-FAST-056

\subsection{REFERENCES}

1. Magnuson, D. W., "Critical Three Dimensional Arrays of Neutron Interacting Units, Part IV: Arrays of U(93.2) Metal Reflected by Concrete and Arrays Separated by Vermiculite and Reflected by Polyethylene," Y-DR-109 (1973).

2. Thomas, J. T., "Critical Three Dimensional Arrays of Neutron Interacting Units, Part II: U(93.2) Metal," ORNL-TM-868 (1964).

3. Magnuson, D. W., "Critical Three Dimensional Arrays of Neutron Interacting Units, Part III: Arrays of U(92.3) Metal Separated by Various Materials,” Y-DR-83 (1972).

4. Diaz-Ortiz, A., Stolk, J., Kim, J., Sanchez, J. M., and Manthiram, A., "Characterization of Celotex and Thermodynamic Calculations of the Formation of Corrosion Precursors on Beryllium," ANRCP1999-16, University of Texas-Austin (April 1999).

5. Thomas, J. T, "Critical Three-Dimensional Arrays of U(93.2)-Metal Cylinders," Nucl. Sci. Eng., 52, 350-359 (1973). 
NEA/NSC/DOC/(95)03/II

Volume II

HEU-MET-FAST-056

\section{APPENDIX A: TYPICAL INPUT LISTINGS}

Monte Carlo N-Particle (MCNP) version 5.1.51 calculations were utilized for calculating results in this evaluation. MCNP is a general-purpose, continuous-energy, generalized-geometry, time-dependent, coupled n-particle Monte Carlo transport code. The Evaluated Neutron Data File library ENDF/B-VII.0 was utilized in analysis of the experiment and benchmark model biases and uncertainties. The MCNP5 calculations were performed with 4,150 generations with 50,000 neutrons per generation. The $k_{\text {eff }}$ estimates did not include the first 150 generations and the statistical uncertainty in $\mathrm{k}_{\mathrm{eff}}$ for is 0.00005 .

\section{A.1 MCNP Input Listing}

\section{A.1.1 Experiment 18}

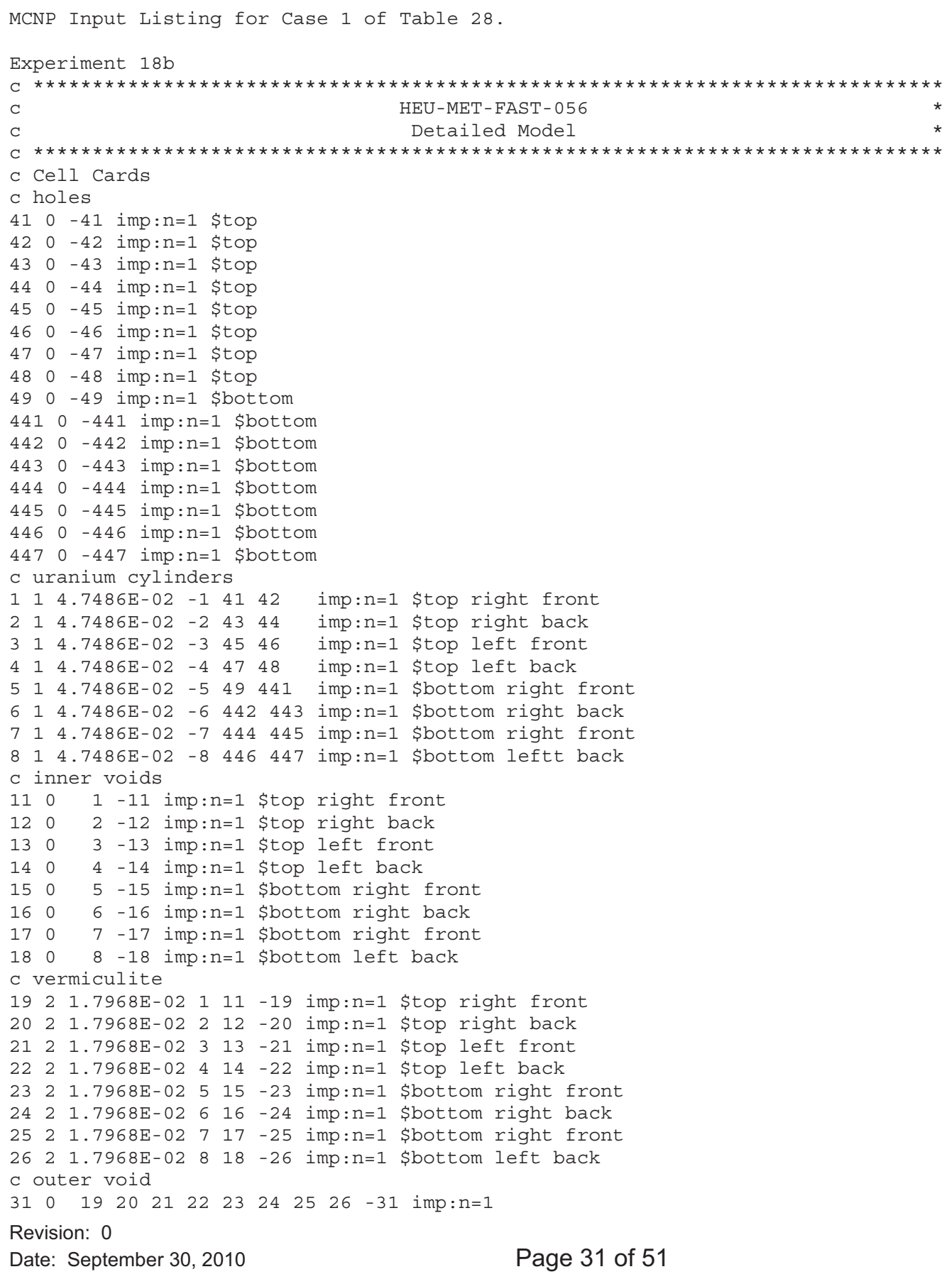


C polyethylene

$\begin{array}{lllllllllllllll}32 & 3 & -0.941 & -32 & 19 & 20 & 21 & 22 & 23 & 24 & 25 & 26 & 31 & -32 & \text { imp:n=1 }\end{array}$

C outside problem area

33032 imp: $\mathrm{n}=0$

C Surface Cards

c cylinder holes

$\begin{array}{llllllllll}41 & \text { rCC } & 7.1565 & 11.43 & 5.08 & 0 & 0 & 10.8 & 0.254 & \text { \$top front }\end{array}$

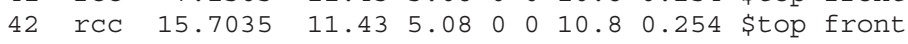

$43 \quad$ rCC $\quad 7.1565-11.43 \quad 5.08 \quad 0 \quad 0 \quad 10.8 \quad 0.254$ \$top back

$44 \quad$ rec $15.7035-11.43 \quad 5.08 \quad 0 \quad 0 \quad 10.8 \quad 0.254$ \$top back

$\begin{array}{llllllllll}45 & \text { rCC } & -7.1565 & 11.43 & 5.08 & 0 & 0 & 10.8 & 0.254 & \text { \$top front }\end{array}$

$\begin{array}{lllllllll}46 & \text { rCC } & -15.7035 & 11.43 & 5.08 & 0 & 0 & 10.8 & 0.254\end{array}$ \$top front

$\begin{array}{lllllllll}47 & \text { rCC } & -7.1565 & -11.43 & 5.08 & 0 & 0 & 10.8 & 0.254\end{array}$ \$top back

$48 \quad$ rCC $-15.7035-11.43 \quad 5.08 \quad 0 \quad 0 \quad 10.8 \quad 0.254$ \$top back

49 rCC $7.1565 \quad 11.43-17.48 \quad 0 \quad 0 \quad 10.8 \quad 0.254$ \$bottom front

441 rCC $15.7035 \quad 11.43 \quad-17.48 \quad 0 \quad 0 \quad 10.8 \quad 0.254$ \$bottom front

$\begin{array}{llllllllll}442 & \text { rCC } & 7.1565 & -11.43 & -17.48 & 0 & 0 & 10.8 & 0.254 & \text { \$bottom back }\end{array}$

$\begin{array}{lllllllll}443 & \mathrm{rCC} & 15.7035 & -11.43 & -17.48 & 0 & 0 & 10.8 & 0.254\end{array}$ \$bottom back

444 rCC $-7.1565 \quad 11.43 \quad-17.48 \quad 0 \quad 0 \quad 10.8 \quad 0.254$ \$bottom front

$\begin{array}{lllllllll}445 & \text { rCC } & -15.7035 & 11.43 & -17.48 & 0 & 0 & 10.8 & 0.254\end{array}$ \$bottom front

446 rCC $-7.1565-11.43-17.4800010 .8 \quad 0.254$ \$bottom back

$\begin{array}{lllllllll}447 & \text { rCC } & -15.7035 & -11.43 & -17.48 & 0 & 0 & 10.8 & 0.254\end{array}$ \$bottom back

c uranium cylinders

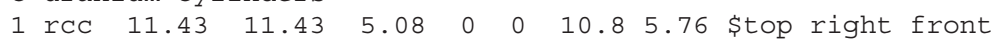

2 rCC $11.43-11.43 \quad 5.08 \quad 0 \quad 0 \quad 10.85 .76$ \$top right back

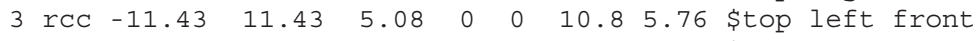

4 rcc $-11.43-11.43 \quad 5.08 \quad 0 \quad 0 \quad 10.85 .76$ \$top left back

$\begin{array}{lllllllll}5 & \text { rCC } & 11.43 & 11.43 & -17.48 & 0 & 0 & 10.8 & 5.76\end{array}$ \$bottom right front

$6 \mathrm{rCC} \quad 11.43-11.43-17.48 \quad 0 \quad 0 \quad 10.8 \quad 5.76$ \$bottom right back

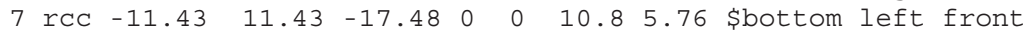

8 rCC $-11.43-11.43-17.48 \quad 0 \quad 0 \quad 10.85 .76$ \$bottom left back

c inner void

$\begin{array}{llllllll}11 & \text { rpp } & 5.4 & 17.46 & 5.4 & 17.46 & 5.08 & 15.88\end{array}$ \$top right front

$\begin{array}{llllllll}12 & \text { rpp } & 5.4 & 17.46 & -17.46 & -5.4 & 5.08 & 15.88\end{array}$ \$top right back

$\begin{array}{llllllll}13 & \text { rpp } & -17.46 & -5.4 & 5.4 & 17.46 & 5.08 & 15.88\end{array}$ \$top left front

14 rpp $-17.46-5.4 \quad-17.46-5.4 \quad 5.08 \quad 15.88$ \$top left back

$\begin{array}{llllllll}15 & \text { rpp } & 5.4 & 17.46 & 5.4 & 17.46 & -17.48 & -6.68\end{array}$ \$bottom right front

16 rpp $5.4 \quad 17.46-17.46-5.4 \quad-17.48 \quad-6.68$ \$bottom right back

17 rpp $-17.46-5.4 \quad 5.4 \quad 17.46-17.48-6.68$ \$bottom left front

18 rpp $-17.46-5.4-17.46-5.4-17.48-6.68$ \$bottom left back

C vermiculite

$\begin{array}{llllllll}19 & \mathrm{rpp} & .32 & 22.54 & .32 & 22.54 & 0 & 22.86\end{array}$ \$top right front

$22.54-22.54-.32 \quad 0 \quad 22.86 \quad$ \$top right back

21 rpp $-22.54-.32 \quad .32 \quad 22.54 \quad 0 \quad 22.86 \quad$ \$top left front

22 rpp $-22.54-.32-22.54-.32 \quad 0 \quad 22.86 \quad$ \$top left back

$\begin{array}{llllllll}23 & \text { rpp } & .32 & 22.54 & .32 & 22.54 & -22.86 & 0\end{array}$ \$bottom right front

$24 \quad$ rpp $.32 \quad 22.54 \quad-22.54 \quad-.32 \quad-22.86 \quad 0$ \$bottom right back

25 rpp $-22.54-.32 \quad .32 \quad 22.54-22.86 \quad 0 \quad$ \$bottom left front

26 rpp $-22.54-.32-22.54-.32-22.86 \quad 0$ \$bottom left back

c outer void

$\begin{array}{llllllll}31 & \text { rpp } & -22.86 & 22.86 & -22.86 & 22.86 & -22.86 & 22.86\end{array}$

C polyethylene

$\begin{array}{llllllll}32 & \text { rpp } & -37.86 & 37.86 & -37.86 & 37.86 & -37.86 & 37.86\end{array}$

C Data Cards

kcode 500001.01504150

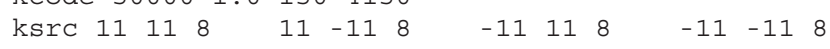

C Materials

$\begin{array}{llllllllllll}11 & 11 & -17 & 11 & -11 & -17 & -11 & 11 & -17 & -11 & -11 & -17\end{array}$

C Uranium $\mathrm{p}=4.7675 \mathrm{E}-02$

m1 92234.00C 4.7911E-04 92235.00C 4.4463E-02 92236.00C 9.5008E-05 $92238.00 \mathrm{C} 2.6378 \mathrm{E}-03$

C Vermiculite $\mathrm{p}=1.7968 \mathrm{E}-02$

m2 1001.00 5.8593E-03 1002.00C 6.7390E-07 6000.00 2.6700E-03 $7014.00 \mathrm{C} \quad 1.7636 \mathrm{E}-03 \quad 7015.00 \mathrm{C} \quad 6.3720 \mathrm{E}-06 \quad 8016.00 \mathrm{C} \quad 6.2276 \mathrm{E}-03$ $8017.00 \mathrm{C} \quad 2.3674 \mathrm{E}-06 \quad 12024.00 \mathrm{C} \quad 3.1596 \mathrm{E}-04 \quad 12025.00 \mathrm{C} \quad 4.0000 \mathrm{E}-05$ $12026.00 \mathrm{C} \quad 4.4040 \mathrm{E}-05$ 13027.00C $2.5000 \mathrm{E}-04$ 14028.00C $5.3493 \mathrm{E}-04$ $14029.00 \mathrm{C} 2.7163 \mathrm{E}-0514030.00 \mathrm{C}$ 1.7906E-05 17035.00C $4.3952 \mathrm{E}-06$ $17037.00 \mathrm{C} 1.4048 \mathrm{E}-06 \quad 19039.00 \mathrm{C} \quad 5.1292 \mathrm{E}-05$ 19040.00C $6.4350 \mathrm{E}-09$ $19041.00 \mathrm{C} 3.7016 \mathrm{E}-06 \quad 20040.00 \mathrm{C} \quad 1.9388 \mathrm{E}-05 \quad 20042.00 \mathrm{C} 1.2940 \mathrm{E}-07$ $20043.00 \mathrm{C} 2.7000 \mathrm{E}-08$ 20044.00C $4.1720 \mathrm{E}-07$ 20046.00C 8.0000E-10 


\section{NEA/NSC/DOC/(95)03/II \\ Volume II}

\section{HEU-MET-FAST-056}

$20048.00 \mathrm{C} 3.7400 \mathrm{E}-08 \quad 22046.00 \mathrm{C} 2.8050 \mathrm{E}-06 \quad 22047.00 \mathrm{C} 2.5296 \mathrm{E}-06$ $22048.00 \mathrm{C} 2.5065 \mathrm{E}-0522049.00 \mathrm{C} 1.8394 \mathrm{E}-06 \quad 22050.00 \mathrm{C} 1.7612 \mathrm{E}-06$ $24050.00 \mathrm{C} \quad 1.3485 \mathrm{E}-07 \quad 24052.00 \mathrm{C} \quad 2.5975 \mathrm{E}-06 \quad 24053.00 \mathrm{C} \quad 2.9450 \mathrm{E}-07$ $24054.00 \mathrm{C} 7.3160 \mathrm{E}-08$ 25055.00C $1.9000 \mathrm{E}-06 \quad 26054.00 \mathrm{C} \quad 4.5942 \mathrm{E}-06$ $26056.00 \mathrm{C} 7.2119 \mathrm{E}-05$ 26057.00C $1.6655 \mathrm{E}-06 \quad 26058.00 \mathrm{C} \quad 2.2165 \mathrm{E}-07$ $56130.00 \mathrm{C} 1.0282 \mathrm{E}-08$ 56132.00C 9.7970E-09 56134.00C 2.3445E-07

$56135.00 \mathrm{C} 6.3942 \mathrm{E}-0756136.00 \mathrm{C} 7.6184 \mathrm{E}-07 \quad 56137.00 \mathrm{C} 1.0895 \mathrm{E}-06$

$56138.00 \mathrm{C} 6.9547 \mathrm{E}-06$

c Polyethylene $\mathrm{p}=0.941$ or $0.880 \mathrm{~g} / \mathrm{cm}^{\wedge} 3$

m3 $1001.00 \mathrm{C} 46000.00 \mathrm{C} 2$

mt2 HCH2.00t

mt 3 HCH2.0Ot 


\section{NEA/NSC/DOC/(95)03/II}

Volume II

HEU-MET-FAST-056

\section{APPENDIX B: VERMICULITE IMPURITIES}

Typical vermiculite impurities are summarized in Table B.1. This data is from the Oak Ridge Critical Experiment Logbook 27r, and was specifically found on pages copied and inserted between logbook regular bound pages. There are no page numbers on these pages.

Table B.1. Vermiculite Impurities.

\begin{tabular}{|c|c|c|c|}
\hline Element & Weight (ppm) & Element & "Weight (ppm) \\
\hline $\mathrm{Be}$ & $\begin{array}{ll}<.02 \\
\end{array}$ & " & $\begin{array}{ll}<1.0 \\
\end{array}$ \\
\hline $\mathrm{B}$ & 1.0 & $\mathrm{Tm}$ & $<0.4$ \\
\hline $\mathrm{F}$ & 150.0 & $\mathrm{Yb}$ & $<1.0$ \\
\hline $\mathrm{Na}$ & 800.0 & $\mathrm{Lu}$ & $<0.4$ \\
\hline $\mathrm{P}$ & 10.0 & $\mathrm{Hf}$ & $<1.0$ \\
\hline $\mathrm{S}$ & 20.0 & $\mathrm{Ta}$ & 10.0 \\
\hline $\mathrm{Cl}$ & 1000.0 & $\mathrm{~W}$ & $<1.0$ \\
\hline $\mathrm{Sc}$ & 3.0 & $\mathrm{Re}$ & $<0.7$ \\
\hline $\mathrm{Ti}$ & 14000.0 & Os & $<1.0$ \\
\hline $\mathrm{V}$ & 30.0 & $\mathrm{Ir}$ & $<0.7$ \\
\hline $\mathrm{Cr}$ & 4000.0 & $\mathrm{Pt}$ & 4.0 \\
\hline $\mathrm{Mn}$ & 350.0 & $\mathrm{Au}$ & 1.0 \\
\hline $\mathrm{Fe}$ & 57500.0 & $\mathrm{Hg}$ & $<2.0$ \\
\hline $\mathrm{Co}$ & 40.0 & $\mathrm{Tl}$ & $<0.6$ \\
\hline $\mathrm{Ni}$ & 80.0 & $\mathrm{~Pb}$ & $<0.9$ \\
\hline $\mathrm{Cu}$ & 20.0 & $\mathrm{Bi}$ & $<0.5$ \\
\hline $\mathrm{Zn}$ & 20.0 & Th & $<0.5$ \\
\hline $\mathrm{Ga}$ & 1.0 & $\mathrm{U}$ & $<0.5$ \\
\hline $\mathrm{Ge}$ & 2.0 & $\mathrm{Sn}$ & 2.0 \\
\hline As & 3.0 & $\mathrm{Sb}$ & 1.0 \\
\hline $\mathrm{Se}$ & 2.0 & $\mathrm{Te}$ & 8.0 \\
\hline $\mathrm{Br}$ & 1.0 & I & $<0.3$ \\
\hline $\mathrm{Rb}$ & 250.0 & Cs & 0.9 \\
\hline $\mathrm{Sr}$ & 100.0 & $\mathrm{Ba}$ & 6500.0 \\
\hline $\mathrm{Y}$ & 0.3 & $\mathrm{La}$ & $<0.3$ \\
\hline $\mathrm{Zr}$ & 1.0 & $\mathrm{Ce}$ & 1.0 \\
\hline $\mathrm{Nb}$ & 1.0 & $\operatorname{Pr}$ & $<0.3$ \\
\hline Mo & 3.0 & $\mathrm{Nd}$ & 6.0 \\
\hline $\mathrm{Ru}$ & $<0.7$ & $\mathrm{Sm}$ & 4.0 \\
\hline $\mathrm{Rh}$ & $<0.2$ & $\mathrm{Eu}$ & 2.0 \\
\hline $\mathrm{Pd}$ & $<0.9$ & $\mathrm{Gd}$ & $<2.0$ \\
\hline $\mathrm{Ag}$ & No value given & $\mathrm{Tb}$ & $<0.4$ \\
\hline $\mathrm{Cd}$ & $<0.9$ & Dy & $<1.0$ \\
\hline In & 0.7 & Ho & $<0.4$ \\
\hline
\end{tabular}




\section{APPENDIX C: EVALUATION OF THE AUXILARY CASES}

Benchmark specifications are provided in Section 3 for only one of the experimental configurations, Experiment 18. The only change among the experiments was the amount of vermiculite and the experiment is not overly sensitive to this change. Models of the remaining three experiments, Experiments 19, 20, and 21 are described in this appendix. Sketches of these models are given in Figures C.1 - C.6.

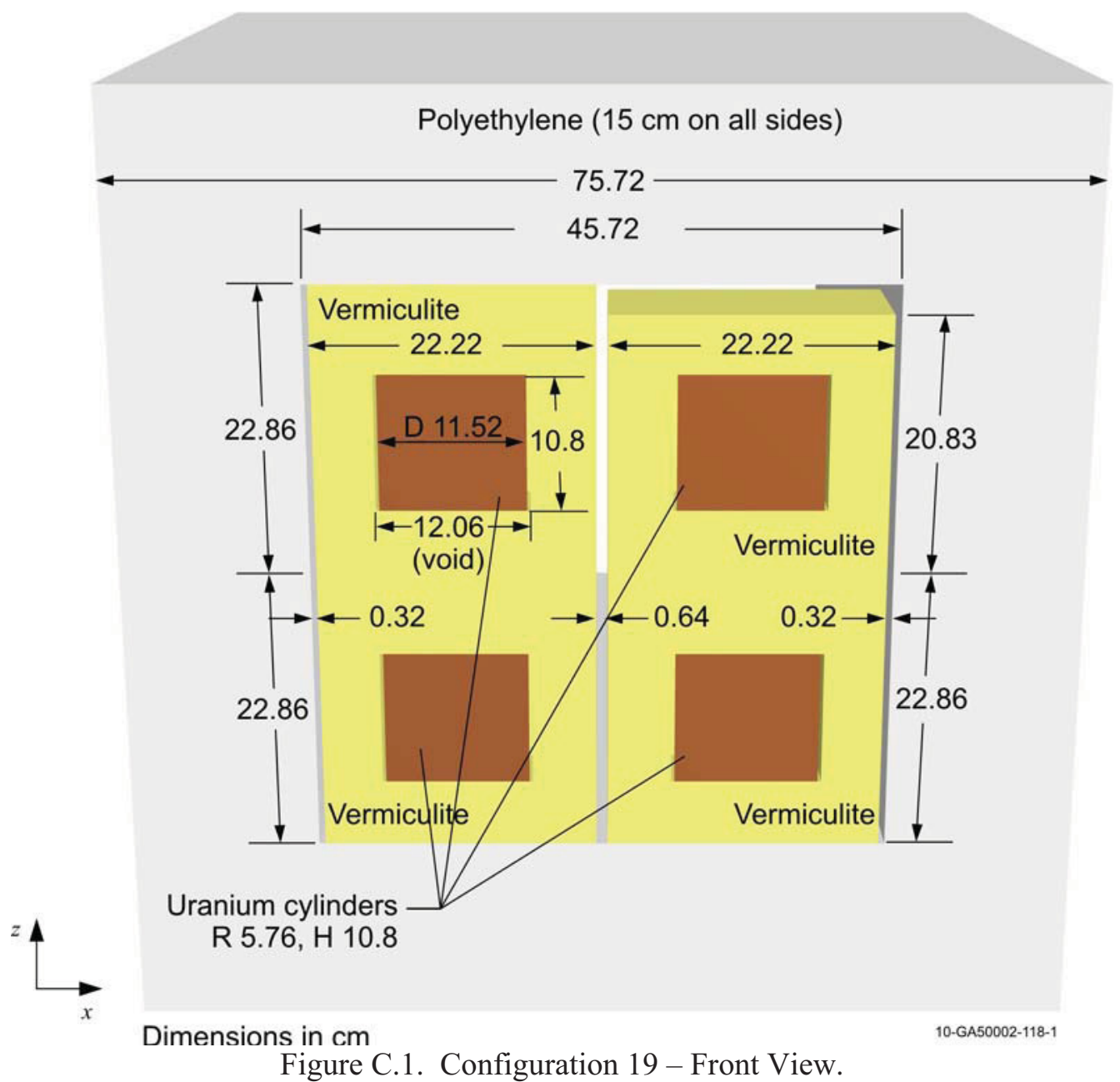




\section{NEA/NSC/DOC/(95)03/II \\ Volume II}

\section{HEU-MET-FAST-056}

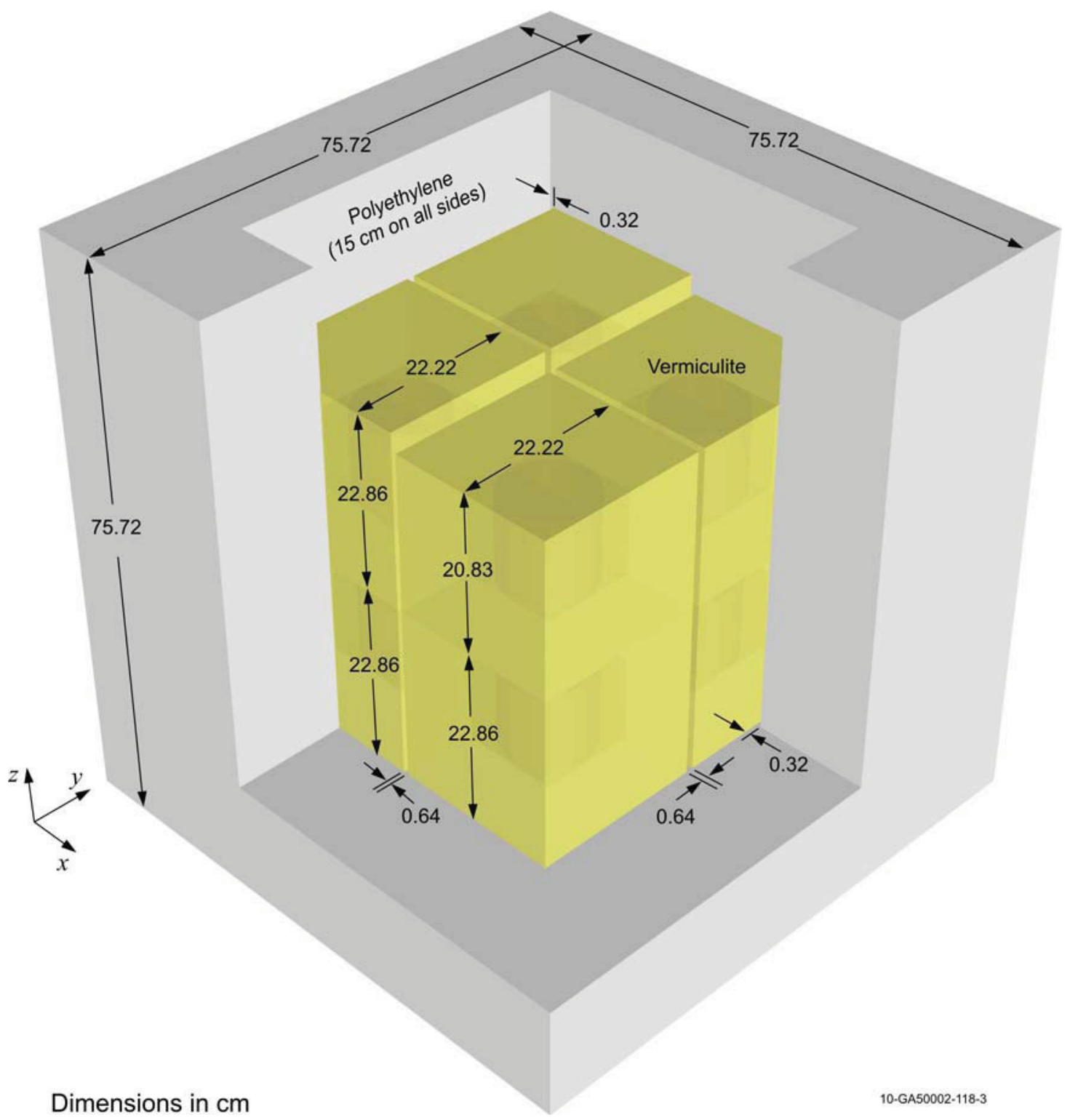

Figure C.2. Configuration 19 - Overview. 
NEA/NSC/DOC/(95)03/II

Volume II

HEU-MET-FAST-056

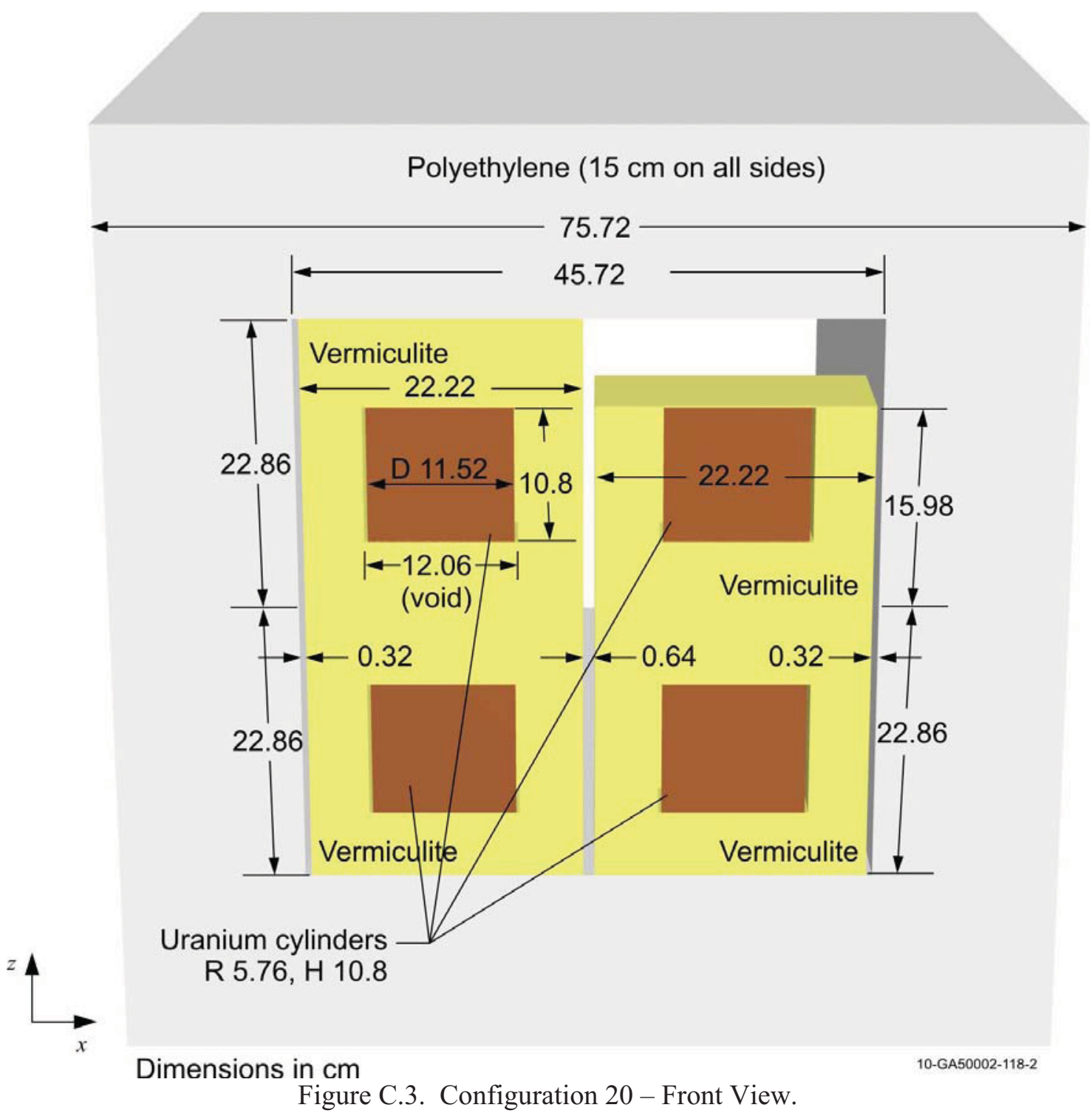




\section{NEA/NSC/DOC/(95)03/II \\ Volume II}

\section{HEU-MET-FAST-056}

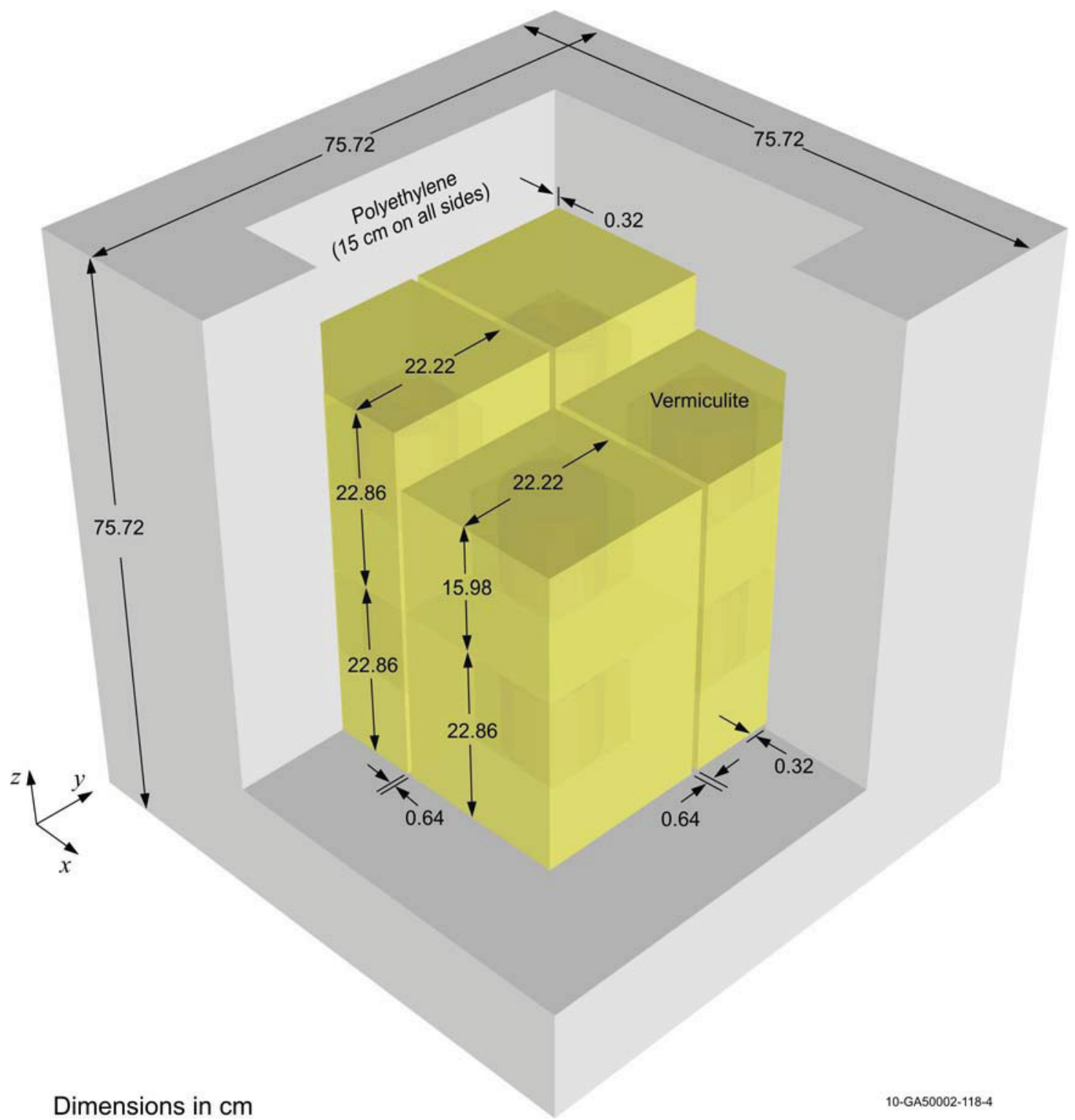

Figure C.4. Configuration 20 - Overview. 
NEA/NSC/DOC/(95)03/II

Volume II

HEU-MET-FAST-056

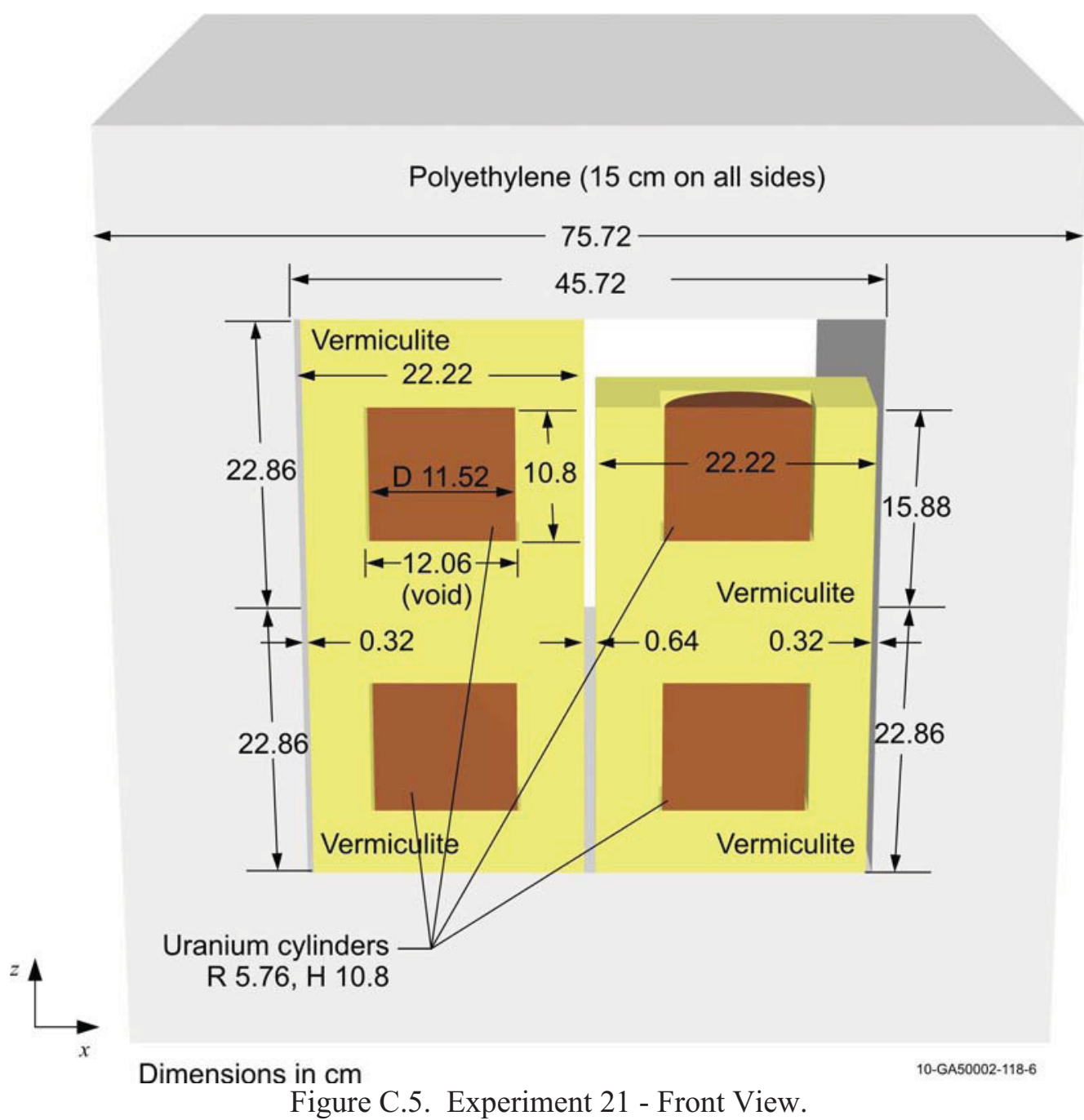

Figure C.5. Experiment 21 - Front View. 


\section{NEA/NSC/DOC/(95)03/II \\ Volume II}

\section{HEU-MET-FAST-056}

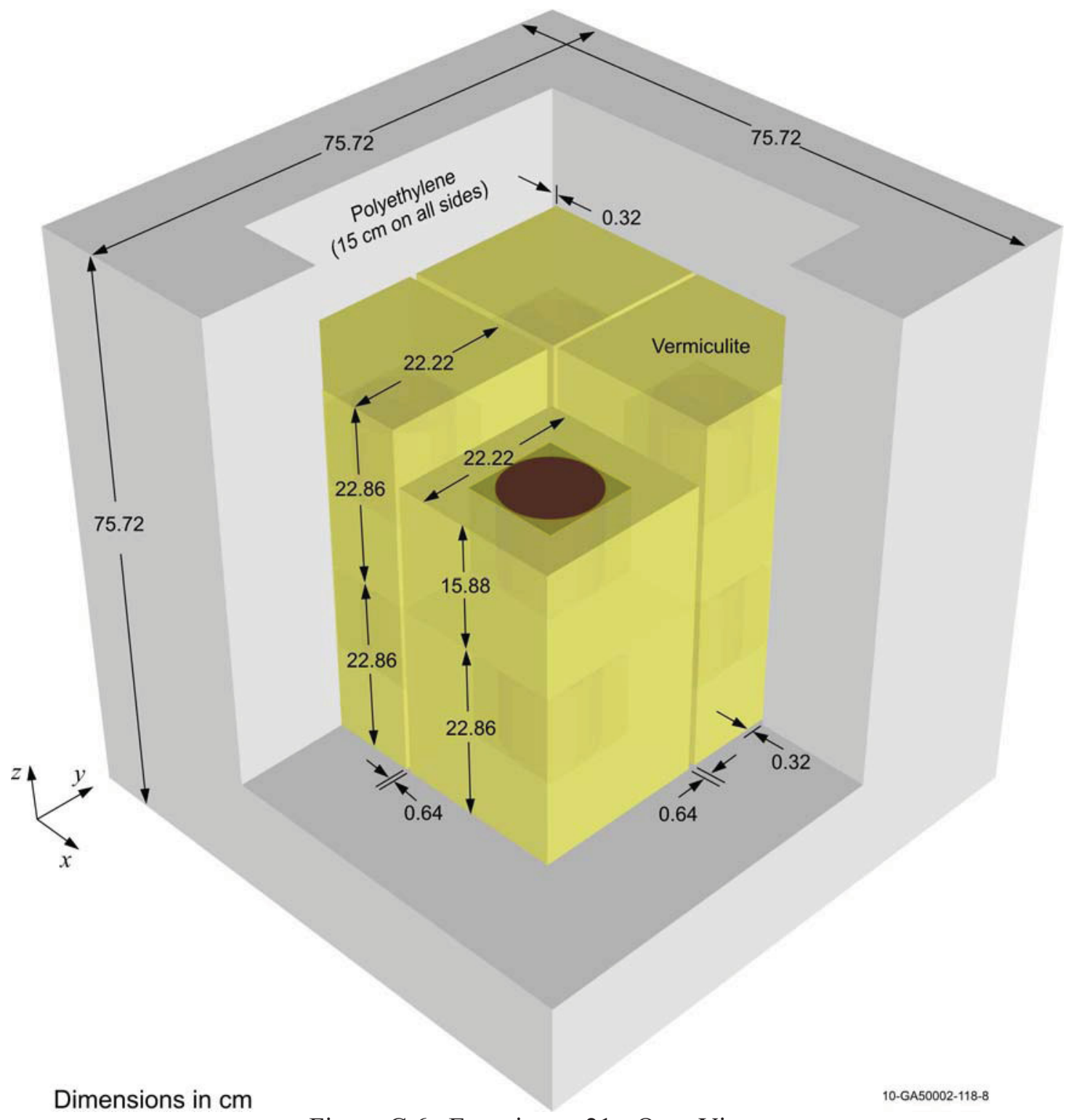

Figure C.6. Experiment 21 - Over View.

All uncertainties for these cases were calculated the same as for Experiment 18. As such, only results will be presented in this appendix. Refer to Section 2 for details regarding calculations and scaling.

Monte Carlo N-Particle (MCNP) version 5.1.51 calculations were utilized to estimate the biases and uncertainties associated with the experimental results in this evaluation. MCNP is a general-purpose, continuous-energy, generalized-geometry, time-dependent, coupled n-particle Monte Carlo transport code. The Evaluated Neutron Data File library ENDF/B-VII.0 was utilized in analysis of the experiment and benchmark model biases and uncertainties. 


\section{C.1.1 HEU Cylinder Uncertainties}

\section{C.1.1.1 HEU Cylinder Mass}

Table C.1. Uranium Mass Uncertainties.

\begin{tabular}{|c|c|c|}
\hline $\begin{array}{c}\text { Experiment } \\
\text { Number }\end{array}$ & $\boldsymbol{\Delta} \mathbf{k}_{\text {calc }}$ & $\begin{array}{c}\text { Uncertainty } \\
\left(\boldsymbol{\Delta} \mathbf{k}_{\text {eff }}\right)\end{array}$ \\
\hline \hline 19 & 0.00013 & 0.00013 \\
\hline 20 & 0.00020 & 0.00020 \\
\hline 21 & 0.00022 & 0.00022 \\
\hline
\end{tabular}

Table C.2. Uranium Density Uncertainties.

\begin{tabular}{|c|c|c|}
\hline $\begin{array}{c}\text { Experiment } \\
\text { Number }\end{array}$ & $\boldsymbol{\Delta} \mathbf{k}_{\text {calc }}$ & $\begin{array}{c}\text { Uncertainty } \\
\left(\boldsymbol{\Delta} \mathbf{k}_{\text {eff }}\right)\end{array}$ \\
\hline \hline 19 & 0.01029 & 0.00182 \\
\hline 20 & 0.00465 & 0.00082 \\
\hline 21 & 0.00562 & 0.00099 \\
\hline
\end{tabular}

\section{C.1.1.2 Placement and Spatial Variation of HEU Cylinders}

Table C.3. Uranium Placement Uncertainties.

\begin{tabular}{|c|c|c|}
\hline $\begin{array}{c}\text { Experiment } \\
\text { Number }\end{array}$ & $\Delta \mathbf{k}_{\text {calc }}$ & $\begin{array}{c}\text { Uncertainty } \\
\left(\boldsymbol{\Delta} \mathbf{k}_{\text {eff }}\right)\end{array}$ \\
\hline \hline 19 & 0.00029 & 0.00017 \\
\hline 20 & 0.00033 & 0.00019 \\
\hline 21 & 0.00028 & 0.00016 \\
\hline
\end{tabular}

\section{C.1.1.3 HEU Isotopic Content}

Table C.3. Uranium Composition Uncertainty.

\begin{tabular}{|c|c|c||}
\hline $\begin{array}{c}\text { Experiment } \\
\text { Number }\end{array}$ & $\Delta \mathbf{K}_{\text {calc }}$ & $\begin{array}{c}\text { Uncertainty } \\
\left(\Delta \mathbf{k}_{\text {eff }}\right)\end{array}$ \\
\hline \hline 19 & 0.00821 & 0.00041 \\
\hline 20 & 0.00571 & 0.0002855 \\
\hline 21 & 0.00471 & 0.0002355 \\
\hline
\end{tabular}




\section{NEA/NSC/DOC/(95)03/II \\ Volume II}

HEU-MET-FAST-056

\section{C.1.1.4 Cylinder Dimensions}

Table C.4. Uranium Dimensional Uncertainties.

\begin{tabular}{|c|c|c|}
\hline $\begin{array}{c}\text { Experiment } \\
\text { Number }\end{array}$ & $\Delta \mathbf{k}_{\text {calc }}$ & $\begin{array}{c}\text { Uncertainty } \\
\boldsymbol{\Delta} \mathbf{k}_{\text {eff }}\end{array}$ \\
\hline \hline 19 & 0.00424 & 0.00050 \\
\hline 20 & 0.00567 & 0.00067 \\
\hline 21 & 0.00427 & 0.00050 \\
\hline
\end{tabular}

\section{C.1.2 Vermiculite Uncertainties}

\section{C.1.2.1 Vermiculite Composition}

Table C.5. Vermiculite Composition Uncertainties.

\begin{tabular}{|c|c|c|}
\hline $\begin{array}{c}\text { Experiment } \\
\text { Number }\end{array}$ & $\boldsymbol{\Delta} \mathbf{k}_{\text {calc }}$ & $\begin{array}{c}\text { Uncertainty } \\
\boldsymbol{\Delta} \mathbf{k}_{\text {eff }}\end{array}$ \\
\hline \hline 19 & 0.00194 & 0.001097 \\
\hline 20 & 0.00229 & 0.00132 \\
\hline 21 & 0.00237 & 0.00137 \\
\hline
\end{tabular}

\section{C.1.2 Vermiculite Impurities}

Table C.6. Vermiculite Impurity Uncertainties.

\begin{tabular}{|c|c|c|}
\hline $\begin{array}{c}\text { Experiment } \\
\text { Number }\end{array}$ & $\boldsymbol{\Delta} \mathbf{k}_{\text {calc }}$ & $\begin{array}{c}\text { Uncertainty } \\
\boldsymbol{\Delta} \mathbf{k}_{\text {eff }}\end{array}$ \\
\hline 19 & 0.0024 & 0.0014 \\
\hline 20 & 0.0029 & 0.0017 \\
\hline 21 & 0.0025 & 0.0014 \\
\hline
\end{tabular}

\section{C.1.2.3 Vermiculite Dimensions}

Table C.7. Vermiculite Dimensional Uncertainties.

\begin{tabular}{|c|c|c|}
\hline $\begin{array}{c}\text { Experiment } \\
\text { Number }\end{array}$ & $\Delta \mathbf{k}_{\text {calc }}$ & $\begin{array}{c}\text { Uncertainty } \\
\boldsymbol{\Delta} \mathbf{k}_{\text {eff }}\end{array}$ \\
\hline 19 & 0.00064 & 0.00037 \\
\hline 20 & 0.00064 & 0.00037 \\
\hline 21 & 0.00067 & 0.00039 \\
\hline
\end{tabular}




\section{NEA/NSC/DOC/(95)03/II \\ Volume II}

HEU-MET-FAST-056

\section{C.1.2.4 Vermiculite Density}

No uncertainty information was provided for the density of the vermiculite separating sheets. The provided density was $0.34 \mathrm{~g} / \mathrm{cm}^{3}$. To evaluate the effect of the density on the experiment, half of the last significant digit was used to vary the density. The results were completely negligible, before using any scaling.

\section{C.1.2.5 Vermiculite Gaps}

Table C.8. Polyethylene Impurities.

\begin{tabular}{|c|c|c|}
\hline $\begin{array}{c}\text { Experiment } \\
\text { Number }\end{array}$ & $\boldsymbol{\Delta} \mathbf{k}_{\text {calc }}$ & $\begin{array}{c}\text { Uncertainty } \\
\boldsymbol{\Delta} \mathbf{k}_{\text {eff }}\end{array}$ \\
\hline 19 & 0.0097 & 0.0097 \\
\hline 20 & 0.0080 & 0.0080 \\
\hline 21 & 0.0088 & 0.0088 \\
\hline
\end{tabular}

\section{C.2 Uncertainties in the Reflector}

\section{C.2.3.1 Reflector Impurities}

Table C.9. Polyethylene Impurities.

\begin{tabular}{|c|c|c|}
\hline $\begin{array}{c}\text { Experiment } \\
\text { Number }\end{array}$ & $\Delta \mathbf{k}_{\text {calc }}$ & $\Delta \mathbf{k}_{\text {eff }}$ \\
\hline 19 & 0.00442 & 0.00255 \\
\hline 20 & 0.00273 & 0.00158 \\
\hline 21 & 0.00166 & 0.00096 \\
\hline
\end{tabular}

\section{C.2.3.2 Thickness of the Reflector}

Table C.10. Polyethylene Dimensions Uncertainties.

\begin{tabular}{|c|c|c|}
\hline $\begin{array}{c}\text { Experiment } \\
\text { Number }\end{array}$ & $\Delta \mathbf{k}_{\text {calc }}$ & $\begin{array}{c}\text { Uncertainty } \\
\boldsymbol{\Delta} \mathbf{k}_{\text {eff }}\end{array}$ \\
\hline 19 & 0.00011 & 0.00006 \\
\hline 20 & 0.00006 & 0.00003 \\
\hline 21 & 0.00004 & 0.00002 \\
\hline
\end{tabular}


NEA/NSC/DOC/(95)03/II

Volume II

HEU-MET-FAST-056

\section{C.2.3.3 Polyethylene Density}

Table C.11. Polyethylene Density Uncertainties.

\begin{tabular}{|c|c|c|}
\hline $\begin{array}{c}\text { Experiment } \\
\text { Number }\end{array}$ & $\boldsymbol{\Delta} \mathbf{k}_{\text {calc }}$ & $\begin{array}{c}\text { Uncertainty } \\
\boldsymbol{\Delta} \mathbf{k}_{\text {eff }}\end{array}$ \\
\hline 19 & 0.00988 & 0.00285 \\
\hline 20 & 0.00740 & 0.00214 \\
\hline 21 & 0.00668 & 0.00193 \\
\hline
\end{tabular}

\section{C.2.4 Uncertainty in the Experimental Measurement of $\mathbf{k}_{\text {eff }}$}

There is no data available regarding the method of determining the critical gap in the split table apparatus, nor is there sufficient information to determine uncertainty in extrapolation to $\mathrm{k}_{\text {eff }}$ for the experimental $\mathrm{k}_{\text {eff }}$ values. To deal with this uncertainty, only one of the experimental configurations was evaluated as a benchmark experiment and the others used to demonstrate reproducibility, variability in the amount of Vermiculite, uncertainty in extrapolation of $\mathrm{k}_{\mathrm{eff}}$ from the gapless configuration.

The reason for treating only one case as a benchmark is because the only difference from one case to the next is the amount of Vermiculite and the experiments are not very sensitive to these permutations. The other three experiments were used to estimate uncertainty in the reported experimental $\mathrm{k}_{\text {eff }}$ value and compare the difference in uncertainties among experiments.

Experiment 18 is the reference case, Case 1a. This case was chosen because for the closed configuration, it is the closest to having an experimental $\mathrm{k}_{\mathrm{eff}}$ of unity. The other experiments are Experiments $19-21$. Table 8 lists Experiments 19, 20, and 21 and their corresponding experimental $k_{\text {eff }}$ value. This table is reproduced below as Table C.12 for convenience.

Table C.12. $\mathrm{k}_{\mathrm{eff}}$.

\begin{tabular}{||c|c|}
\hline $\begin{array}{c}\text { Experiment } \\
\text { Number }\end{array}$ & Reported $\mathbf{k}_{\text {eff }}$ \\
\hline 19 & 1.0007 \\
\hline 20 & 1.0016 \\
\hline 21 & 1.0013 \\
\hline
\end{tabular}

The standard deviation in the reported $\mathrm{k}_{\text {eff }}$ values is 0.0005 , which is treated as representing a $1 \sigma$ uncertainty, which represents the uncertainty in the $\mathrm{k}_{\mathrm{eff}}$ extrapolation from a critical condition with an unspecified gap width to a closed position, and also accounts for experiment repeatability. Similar experiments (HEU-MET-FAST-053) found a similar $1 \sigma$ uncertainty of 0.0003 .

\section{C.2.5 Total Experimental Uncertainty}

The total uncertainty for the experiment was calculated by taking the square root of the sum of all the individual uncertainties discussed in this section. The summarized total uncertainties for each of the auxiliary cases are presented in Table C.13. A negligible value is less than 0.00005 . 


\section{NEA/NSC/DOC/(95)03/II}

Volume II

\section{HEU-MET-FAST-056}

Table C.13. Total Experimental Uncertainty, $\Delta \mathrm{k}_{\text {eff }}$.

\begin{tabular}{|l|c|c|c||}
\hline Uncertainty Parameter & $\mathbf{1 9}$ & $\mathbf{2 0}$ & $\mathbf{2 1}$ \\
\hline \hline Uranium Mass & 0.00013 & 0.0002 & 0.00022 \\
\hline Uranium Density & 0.00182 & 0.00082 & 0.00099 \\
\hline Uranium Placement & 0.00017 & 0.00019 & 0.00016 \\
\hline Uranium Content & 0.00041 & 0.000286 & 0.000236 \\
\hline Uranium Dimensions & 0.0005 & 0.00067 & 0.0005 \\
\hline Vermiculite Composition & 0.001097 & 0.00132 & 0.00137 \\
\hline Vermiculite Impurities & 0.0014 & 0.0017 & 0.0014 \\
\hline Vermiculite Dimensions & 0.00037 & 0.00037 & 0.00039 \\
\hline Vermiculite Density & negligible & negligible & negligible \\
\hline Vermiculite Gaps & 0.0097 & 0.0080 & 0.0088 \\
\hline Polyethylene Impurities & 0.00255 & 0.00158 & 0.00096 \\
\hline Polyethylene Dimensions & negligible & negligible & negligible \\
\hline Polyethylene Density & 0.00285 & 0.00214 & negligible \\
\hline Total Uncertainty & 0.01076 & 0.00878 & 0.00914 \\
\hline
\end{tabular}


NEA/NSC/DOC/(95)03/II

Volume II

HEU-MET-FAST-056

\section{APPENDIX D: SAMPLE INPUT FOR EXPERIMENTS 19, 20, AND 21}

\section{D.1.1 Experiment 19}

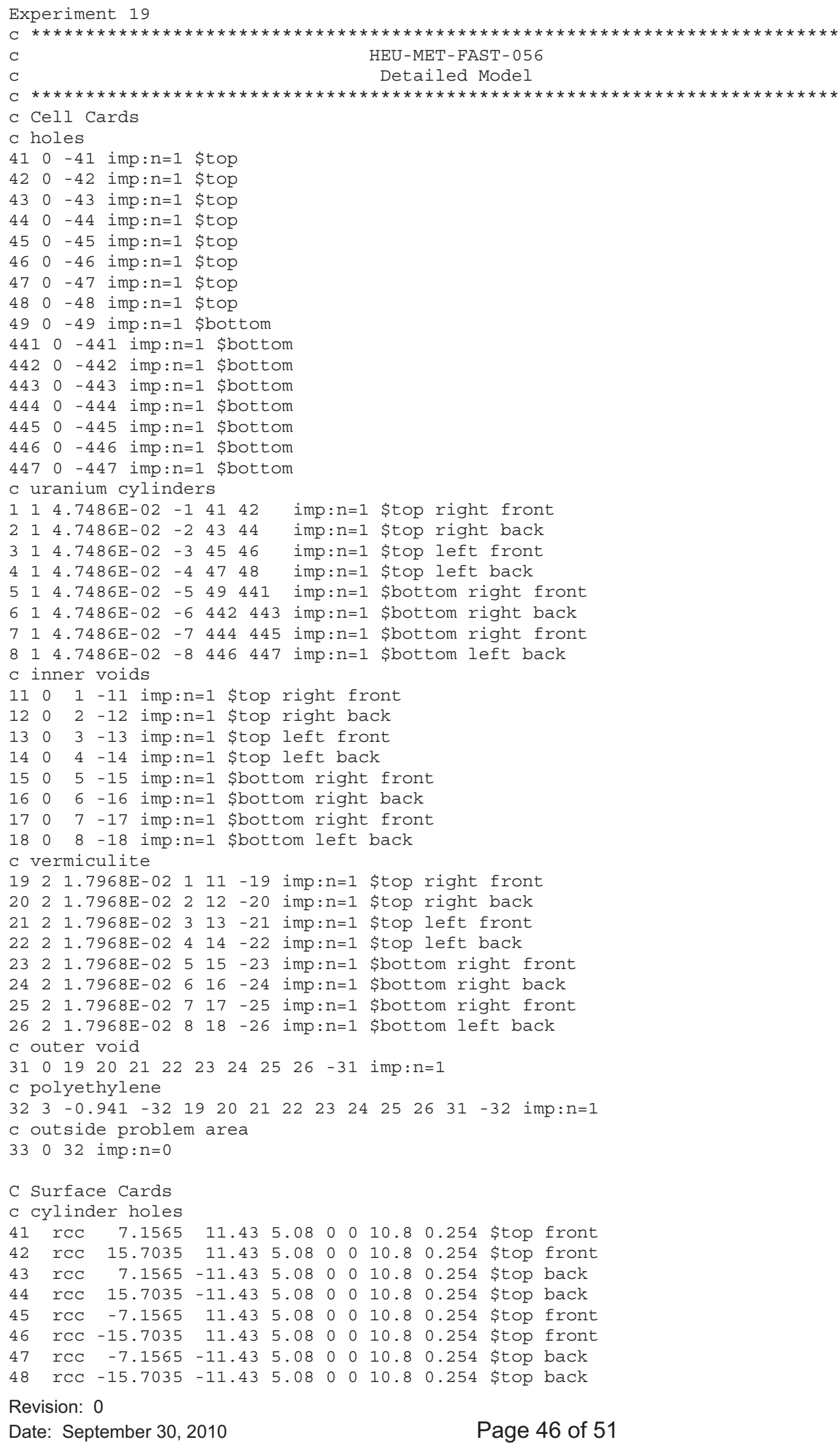


NEA/NSC/DOC/(95)03/II

Volume II

\section{HEU-MET-FAST-056}

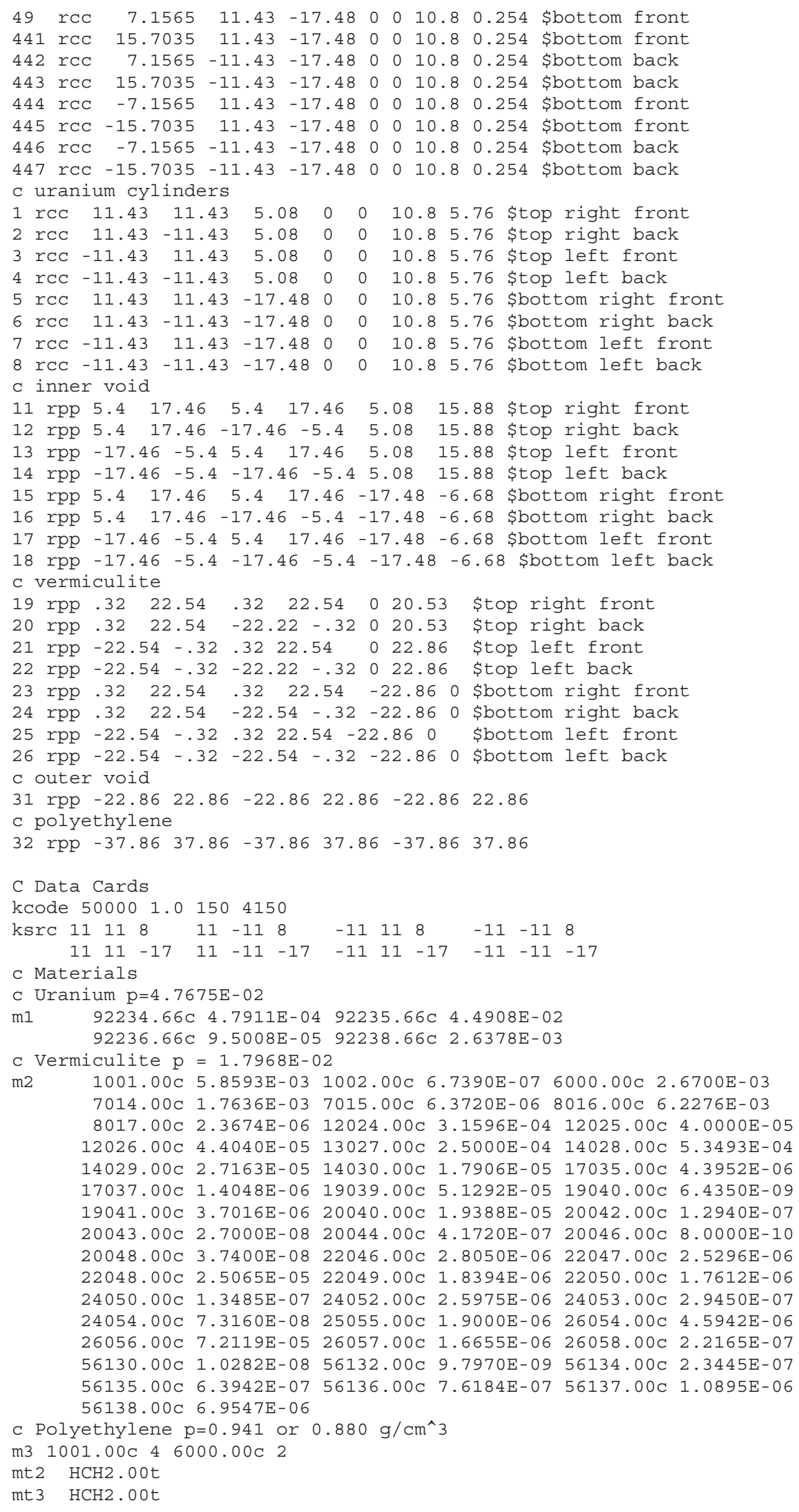


NEA/NSC/DOC/(95)03/II

Volume II

HEU-MET-FAST-056

\section{D.1.2 Experiment 20}

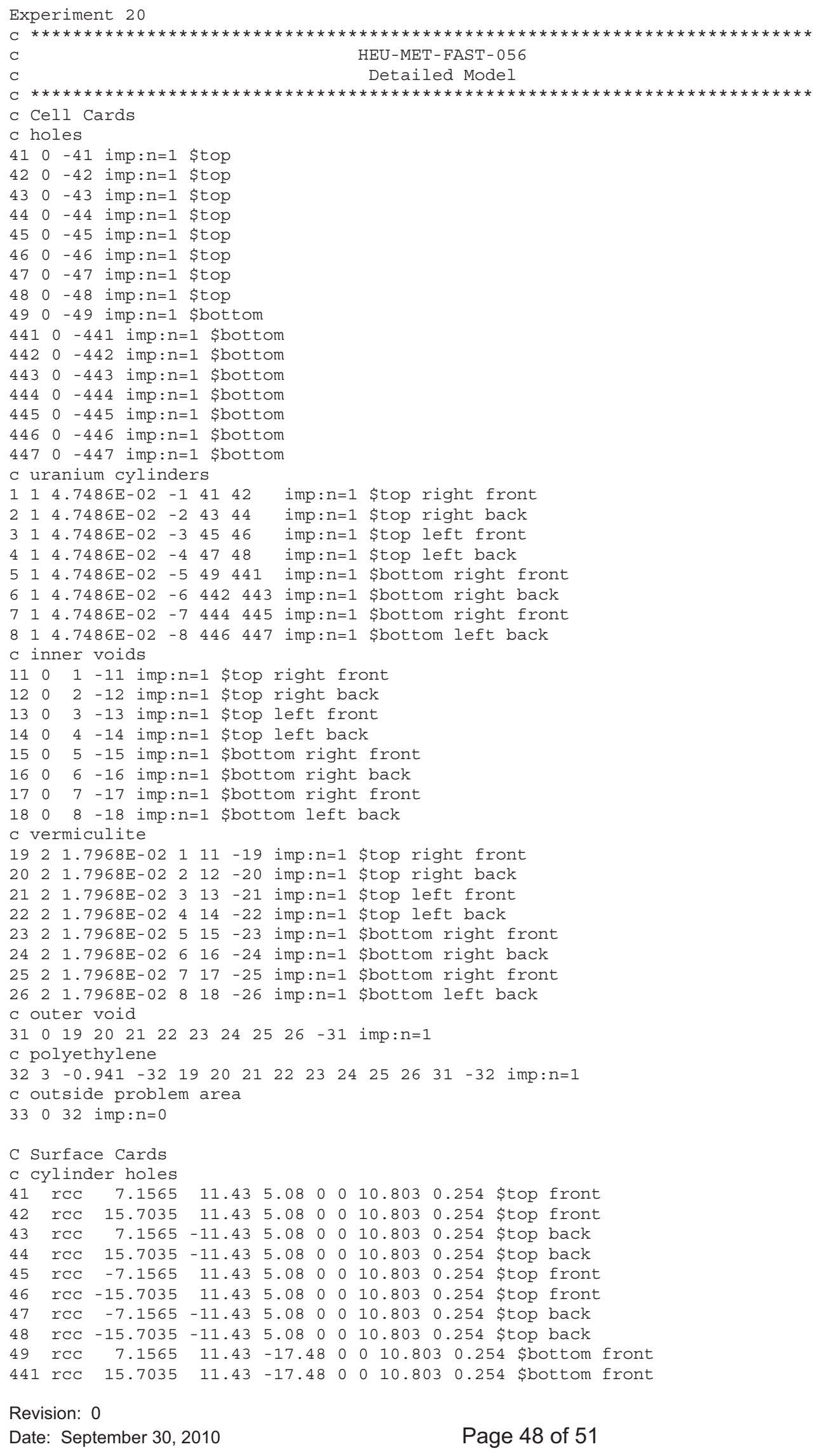

Revision: 0 


\section{NEA/NSC/DOC/(95)03/II}

Volume II

\section{HEU-MET-FAST-056}

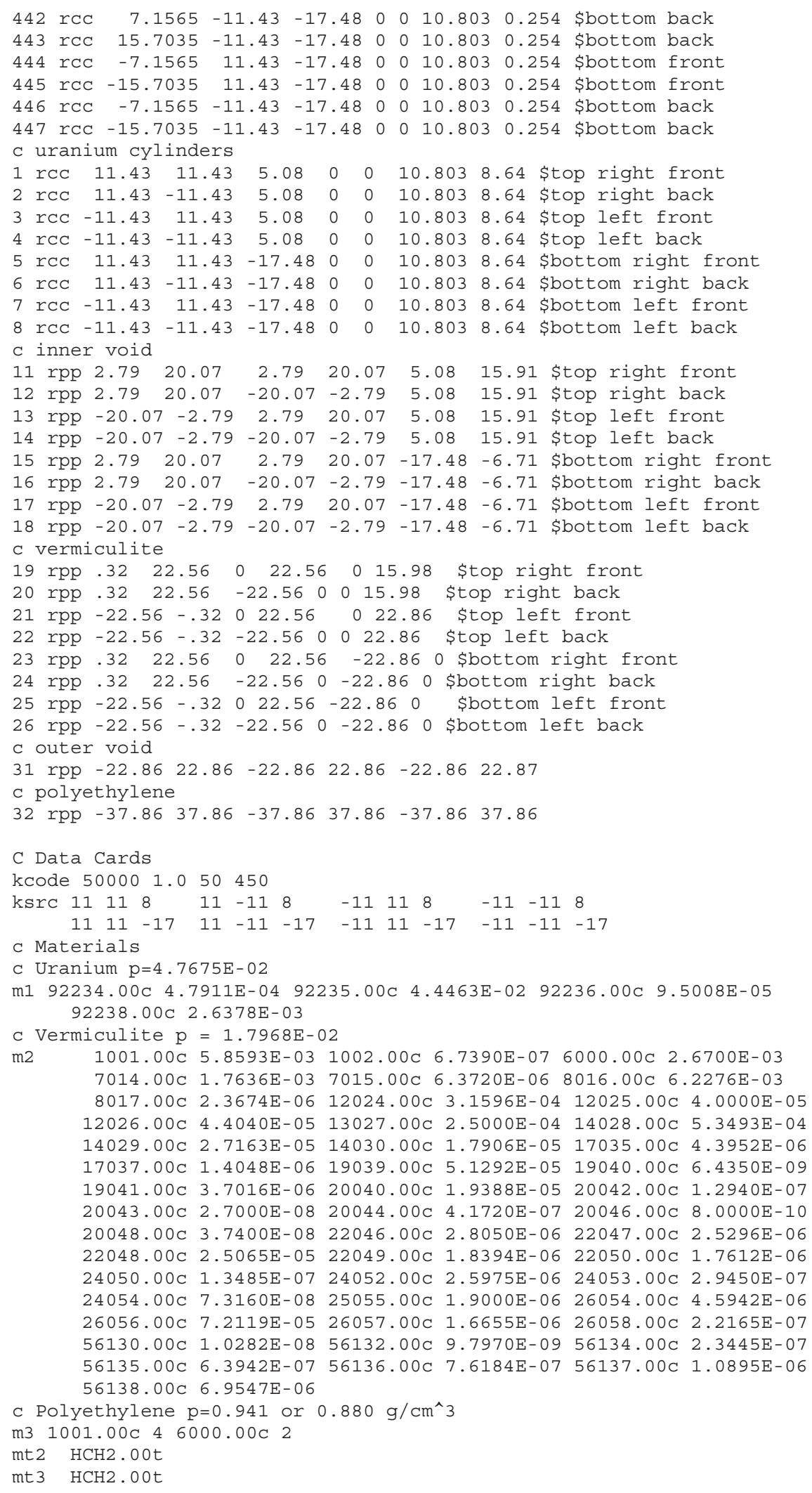


NEA/NSC/DOC/(95)03/II

Volume II

HEU-MET-FAST-056

\section{D.1.3 Experiment 21}

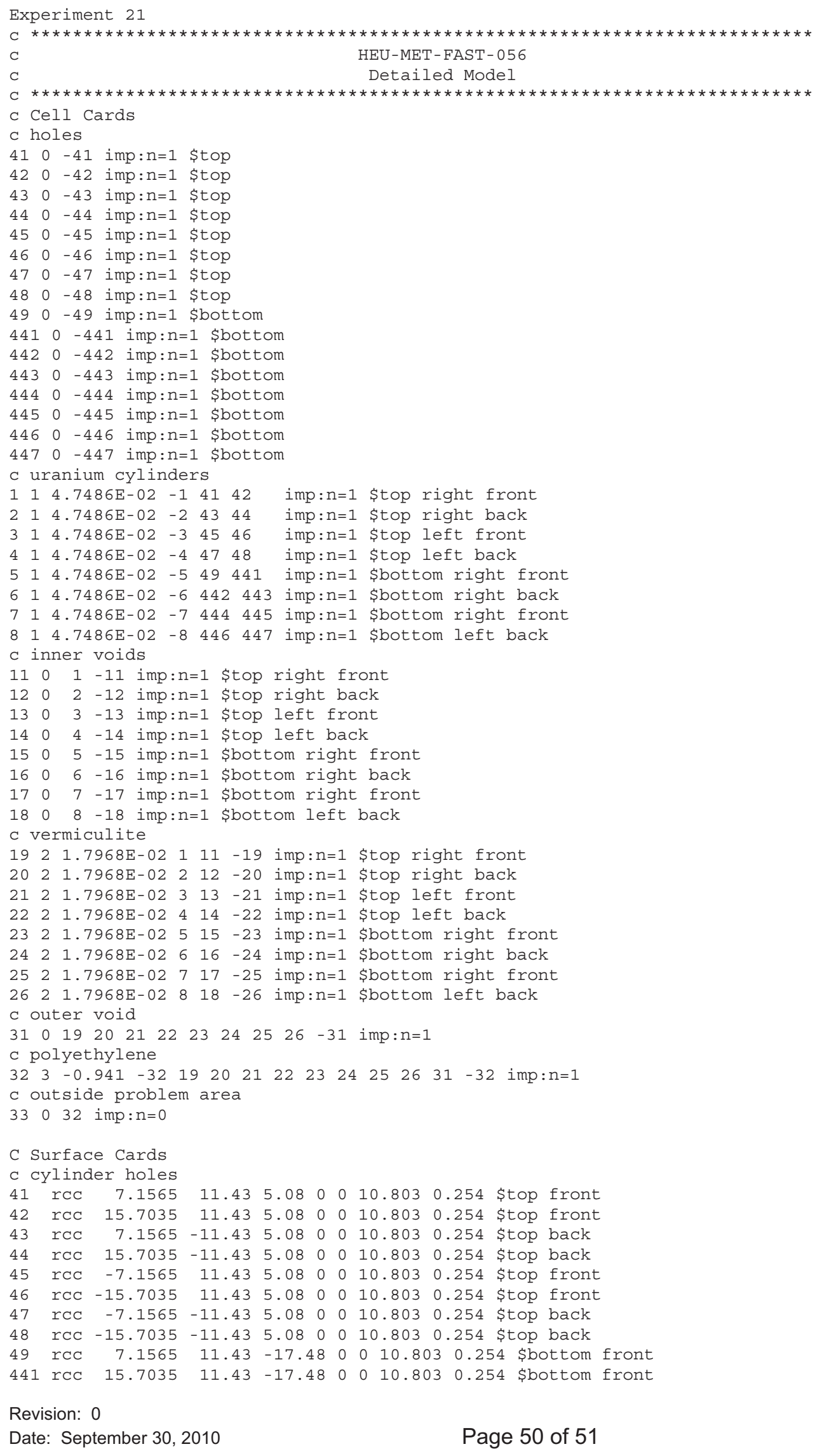

Revision: 0 


\section{NEA/NSC/DOC/(95)03/II}

Volume II

\section{HEU-MET-FAST-056}

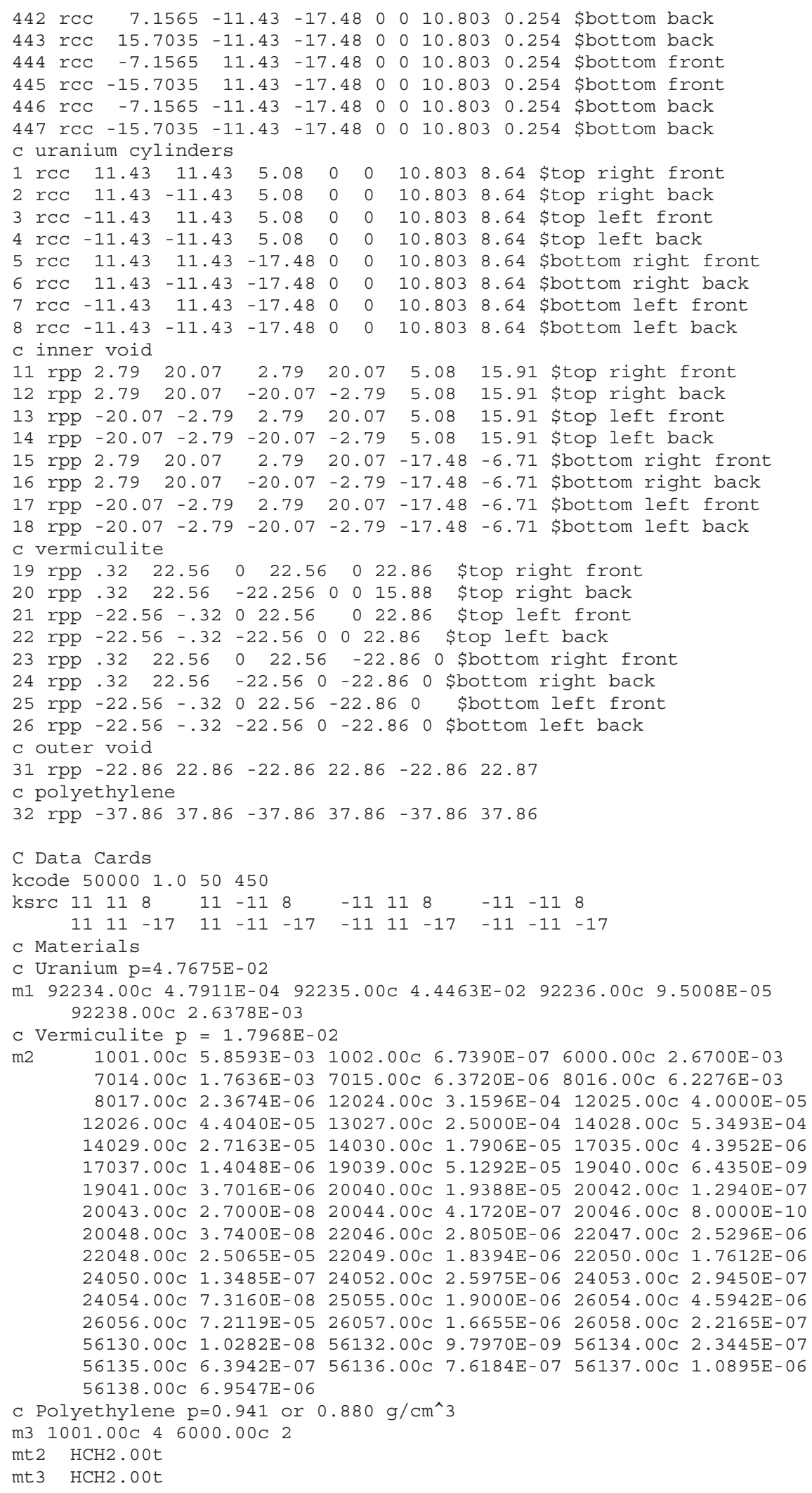

